\title{
ROBUST RESOURCE ADEQUACY PLANNING IN THE FACE OF COAL RETIREMENTS Roger Lueken ${ }^{\dagger, \$^{*}}$, Jay Apt ${ }^{\ddagger \S}$, Fallaw Sowell ${ }^{\ddagger}$
}

† Present address: The Brattle G roup, 1850 M Street NW, Suite 1200, Washington D.C. 20036, USA

$\S$ Department of Engineering and Public Policy, Carnegie Mellon University, Pittsburgh, PA 15213, USA

‡ Tepper School of Business, Carnegie Mellon University, Pittsburgh, PA 15213, USA

*Corresponding Author. E-mail: Roger.Lueken@ brattle.com. Telephone: 202-419-3321.

\section{Notes}

The authors declare no competing financial interest.

\section{Keywords}

resource adequacy; capacity planning; risk; statistical modeling; market design

\begin{abstract}
We investigate the resource adequacy requirements of the PJM Interconnection, and the sensitivity of capacity procurement decisions to the choice of reliability metric used to measure resource adequacy. Assuming that plants fail independently, we find that PJM's 2010 reserve margin of $20.5 \%$ was sufficient to achieve the stated reliability standard of one loss of load event per ten years with $90 \%$ confidence. PJM could reduce reserve margins to 13\% and still achieve adequate levels of reliability as measured by the 2.4 Loss of Load Hours metric and the $0.001 \%$ Unserved Energy metric, which are used by other U.S. and international systems. A reserve margin of 13\% -
\end{abstract}


15\% would minimize long-run system costs. Reducing reserve margins from $20.5 \%$ to $13 \%$ in 2010 would have reduced PJM's capacity procurement by $11 \mathrm{GW}$, the same amount of coal capacity that PJM has identified as at high risk of retirement. We also investigate the risk posed by correlated failures among generators, a risk traditionally not modeled by system planners. We illustrate that three types of correlated failures may increase outage risks: natural gas supply disruptions, reduced reliability among generators during winter months, and the simultaneous shutdown of multiple nuclear generators for regulatory reasons.

\section{INTRODUCTION}

O ver the next decade, significant coal plant retirements are expected in the United States. The Energy Information Agency forecasts that $40 \mathrm{GW}$ of coal capacity will retire between 2014 - 2020 (EIA 2013). These retirements are due to a combination of factors. Many coal plants are near the end of their expected lifespan. Many small and outdated coal plants are finding it cost prohibitive to make the retrofits necessary to comply with emission regulations. Low natural gas prices have put downward pressure on revenues from wholesale electricity prices.

These retirements pose a new challenge to system operators, who are mandated to meet resource adequacy requirements. To meet these requirements, systems procure generation capacity that is rarely used but is needed in extreme circumstances. This capacity, typically natural gas combustion turbines, has low upfront capital costs but high operating costs. In the traditional regulated utility model, these generators are compensated through rate-of-return ratemaking, even if they produce no power. The restructuring of 20 U.S. states in the late 1990s and early 2000s led the industry to recognize the so-called "missing money problem", whereby market designs would not support sufficient generation investment (Joskow 2006, Joskow 2008, Spees et al. 2013). Today, many restructured markets use capacity markets to compensate generators for the capacity they provide. Since 2007, PJM has procured capacity through its centralized capacity market. Capacity 
market billings were $\$ 8$ billion in both the 2009/ 2010 and 2010/ 2011 auctions. In 2010, capacity costs were roughly $18 \%$ of total 2010 billings (PJM 2011a).

Resource adequacy modeling underpins the planning decisions made in today's electricity systems. In both traditionally regulated states with Integrated Resource Planning processes and restructured states with ISO -administered capacity markets, resource adequacy models play a major role in determining the amount of capacity that is built. These models consider the reliability of existing generators and forecasts of load. Both generator outages and load forecasts are highly uncertain, creating the risk that inaccurate modeling may lead to an over- or under-procurement of capacity. O ver-procuring capacity will increase costs for ratepayers; under-procuring capacity will create outage risks above reliability targets.

The traditional metric of resource adequacy is the number of loss of load events (LO LE) per ten years. Most U.S. systems, including the PJM Interconnection, procure enough capacity to meet a LO LE standard of one expected event per ten years, or 0.1 events per year (0.1 LO LE standard) (PJM 2013). The 0.1 LOLE standard dates back to the 1950s, although its origins are unknown (EISPC 2013, Pfeifenberger et al. 2013). Here we follow the standard definition of an outage "event" as an outage lasting one or more consecutive hours. The LO LE metric is problematic, because it considers neither the duration of an outage nor the magnitude of load shed during an outage.

Instead of the LO LE metric, some systems have adopted other standards. The Southwest Power Pool (SPP) uses the metric of 24 expected loss of load hours (LOLH) per ten years, or 2.4 hours per year (2.4 LOLH standard) (EISPC 2013). The Scandinavian system uses the metric of expected unserved energy (UE) totaling $0.001 \%$ of total load served (0.001\% UE standard). Australia's National Energy Market (NEM) and South West Interconnected System (SWIS) have 
adopted a 0.002\% UE standard (Pfeifenberger et al. 2013). The North American Electric Reliability Corporation has recommended system operators adopt UE standards, as they explicitly consider the magnitude of outages (NERC 2010). All three metrics consider only the risk of generator outages, and exclude other risks such as transmission or distributions outages.

Although a significant body of literature exists on the electric system reliability, resource adequacy risks have received less attention. As part of a study into electricity reliability more broadly, (Hines et al. 2009) find that supply shortages over the period 1984 - 2006 were responsible only for $2.3 \%$ of U.S. outage events. The methods used by system planners today are very similar to those outlined by Billinton in the 1970s (Billinton et al. 1973). More recently, system planners have begun to analyze the economically optimal reserve margin, or the reserve margin that minimizes total system costs and outage costs (Pfeifenberger et al. 2013, Newell et al. 2014).

In this paper, we analyze the resource adequacy requirements of the PJM Interconnection. We evaluate the sensitivity of requirements to the choice of metric used to measure resource adequacy: LOLE, LOLH, and Unserved Energy. Because the choice of reliability metric is somewhat arbitrary, it would behoove system operators in PJM and elsewhere to understand how capacity procurements may change under different resource adequacy metrics. We also evaluate the reserve margin that results in the lowest long-run system costs, known as the economically optimal reserve margin. We develop a robust statistical model of resource adequacy in PJM for the year 2010. The model consists of a probabilistic forecast of hourly load and a probabilistic forecast of generator outages. The load model explicitly considers three major drivers of uncertainty: uncertain load growth, natural temperature variability, and uncertainty in the underlying model/ process. The load model uses ten years of load data and sixty years of temperature data from Pittsburgh International Airport and Reagan National Airport. We combine the load and outage models into a probabilistic forecast of supply shortages. The model is structurally similar to the model used by PJM to forecast 
load. The intent of this model is not to improve upon PJM's load forecasting methods. Rather, the intent is to allow us to explore the sensitivity of PJM's load procurement decisions to factors including the choice of reliability metric, how likely they wish to meet the target, and risk of correlated failures among generators.

In 2010, PJM calculated a 15.5\% reserve margin was needed to achieve the 0.1 LO LE standard. PJM procured additional capacity, making the realized reserve margin $20.5 \%$. We find that PJM's 15.5\% reserve margin target met the 0.1 LO LE standard. By procuring additional capacity such that the actual reserve margin was 20.5\%, PJM's met the 0.1 LOLE standard with $90 \%$ confidence. Switching to the $2.4 \mathrm{LOLH}$ or $0.001 \%$ UE standard would allow PJM to reduce reserve margins to $13 \%$ and maintain current risk preferences. This represents an $11 \mathrm{GW}$ reduction in capacity from a $20.5 \%$ reserve margin. PJM anticipates $11 \mathrm{GW}$ of coal capacity, or $~ 7 \%$ of total capacity, is "at high risk" of retirement (PJM 2011b). We find that this $11 \mathrm{GW}$ of high risk coal capacity could retire if PJM were to switch to the LOLH or UE metric. We also find that the economically optimal reserve margin in PJM was 13\% - 15\%, which would minimize long-run total system costs, including costs for energy, capacity, reserve shortages, and outages.

An emerging source of risk in power systems is the risk of multiple generators failing simultaneously due to an external forcing event. Traditional system planning assumes plant fail independently of one another. The risk of correlated generator failures was exposed in January 2014, when extreme cold temperatures in the Northeast and Mid-A tlantic forced many generators offline simultaneously due to fuel shortages and mechanical failures and threatened reliability (PJM 2014c). PJM and other systems are working to reduce the risks posed by winter fuel supply disruptions. However, other types of correlated failure risks exist, including extreme weather and natural disasters. Unfortunately, quantifying the likelihood and magnitude of such correlated failures is difficult due to their infrequency. 
We illustrate the potential risks posed by three types of correlated failures: (1) natural gas supply disruptions that force all gas generators offline, (2) increased outage rates among all plants during winter months due to mechanical and fuel supply issues, and (3) the forced shutdown of all PJM nuclear generators by regulators, such as happened in Japan post-Fukushima. We do not attempt to quantify how likely such correlated failures may be. Rather, we vary the likelihood of correlated failures occurring and see the effect on reliability. We find that such low probability but high impact correlated failures may have a large effect on reliability, and may cause PJM and other system operators to overstate reliability.

We also find that the distribution of outage size is 'fat tailed', and the largest $10 \%$ of outages account for half of total load shed. Therefore, system operators should recognize that supply shortages are more rare, but more disruptive than implied by reliability metrics.

\section{MethodS}

We develop a probabilistic forecast of supply shortages in PJM for 2010. This forecast consists of two separate analyses: a probabilistic simulation of hourly load, and a probabilistic simulation of capacity available at each hour. These analyses are described in detail below. We then use Monte Carlo analysis to find the probability that load exceeds supply for each hour of the year. We analyze three reliability metrics: LO LE, LOLH, and UE, and their sensitivity to PJM's reserve margin. We perform several sensitivity analyses, and compare the results of our simulation to PJM's modeling of capacity needs.

\subsection{Load forecast}

We use historic load and temperature data to forecast load in PJM. Load forecasts have three sources of uncertainty: uncertainty in load growth, natural temperature variability, and uncertainty in the underlying model/ process. We consider each separately to robustly forecast load. 
A large literature exists on forecasting load. Techniques commonly used include regression analysis, time-series analysis, and neural networks (PJM 2013, Hagan and Behr 1987, Hippert et al. 2001). The model used by PJM to set reserve margin targets is a probabilistic model derived from Billinton (PJM 2003, Billinton et al. 1973). The model is not regression based, but uses heuristics that PJM has developed over time. PJM uses a separate regression model to forecast long-term load growth (PJM 2013).

We use regression analysis to forecast hourly load in PJM. The regression model shares many features in common with the regression model PJM uses to forecast long-term load growth. Regression analysis is useful for estimating the expected value of load at each time period. However, our focus is extreme events, i.e. high-load hours in which outages are more likely. To account for these extreme events, we bootstrap the model's residuals to simulate uncertainty in load at each time period.

We forecast hourly load in 2010 using hourly data from the previous ten years. Using ten years of load data allows us to develop a robust relationship between load and other explanatory variables. Hourly load data are from PJM (PJM 2014a). Hourly temperature and associated weather data is from the National O ceanic and Atmospheric Association (NOAA) for the Reagan National Airport and Pittsburgh International Airport weather stations (NOAA 2014a). These weather stations were chosen as they have reliable temperature data available dating back to the 1940s, which is used to forecast 2010 temperatures. Data on the minutes of daylight for each day is from (US Naval Observatory, 2012) for Washington DC.

Since its inception, the PJM territory has undergone several expansions (Table 1). To account for these expansions, we forecast load separately for "PJM Classic" (the PJM region prior to any 
expansions) and each expansion zone. We then combine the forecasts into an overall PJM load forecast.

For each zone, the analysis has the following seven steps:

\section{Step 1: Regress long-term trend}

We first identify and remove the ten year, long-term trend in load growth. By removing the long-term trend, we are able to explicitly incorporate PJM's forecast of future load growth (step 6). To remove the long-term trend, we use a non-parametric, additive model and regress load against the hour index, as shown in Eq. (1)1. The hour index starts at 1 for the first hour of 2000, and ends at the last hour of 2009. Using an additive model allows us to account for nonlinearities in load growth, and regressing the logarithm of load allows us to account for higher variability at high-load hours. The model's residuals are stationary. We use these residuals in step 2 to control for additional explanatory variables that can cause load to vary throughout the year, including temperature and holidays. Figure 1 shows the long-term trend of "PJM Classic", the original PJM footprint, and the model's stationary residuals.

$$
\log \left(\operatorname{load}_{t}\right)=f(t)+\beta_{t}
$$

\section{Step 2: Regress stationary time series}

The second step is to regress $\beta_{\mathrm{t}}$, the stationary residuals from step 1 , on explanatory variables, including calendar events such as major holidays and weekends, temperature, and length of daylight hours. This is shown in Eq. (2). For hour of the day and length of daylight hours, we include interaction terms with the month of the year to account for changes in electric load patterns

\footnotetext{
${ }^{1}$ The non-parametric function $f(\cdot)$ is estimated using $\mathrm{R}$ software and gam command from 'gam' package in $\mathrm{R}$ with default settings where splines are used for the non-parametric estimation, see (Hastie, 2013).
} 
throughout the year. Table A.2 lists all explanatory variables. We use model's residuals, $\gamma_{t}$ to account for uncertainty in the underlying model/ process (see step 7).

$\beta_{t}=\gamma_{1}$ weekday $+\gamma_{2}($ hour $*$ month $)+\gamma_{3}$ holidays $+\gamma_{4}$ Tadj, avg ${ }_{D}+\gamma_{5}($ daylightHours $*$ month $)+\gamma_{t}$

We use hourly weather data to calculate the Tadj, $a v g_{D}$, the average daily temperature adjusted for wind chill index (WCI) and temperature humidity index (THI) (Table 3, Equations (3) to (6)). For each region, we use data for either Reagan National Airport (DCA) or Pittsburgh International Airport (PIT) (NOAA 2014a), depending on which is closest (Table 2).

Because the relationship between temperature and load is highly nonlinear (Figure 2), we used a nonlinear, additive term to account for temperature in the regression. The remaining regression terms are linear. We found that using a non-linear model of temperature was more accurate than a linear model of temperature dependence that included both linear and quadratic terms (see Appendix A). As shown in Figure A.2 - Figure A.4, the linear model significantly over-predicts load during high-temperature days. This is because the linear model predicts accelerating growth in load with increasing temperatures. However, load growth actually begins to slow once an average daily temperature of $\sim 27^{\circ} \mathrm{C}$ are reached (Figure 2). This is likely because air conditioning loads start to saturate once temperatures are high enough. This over-prediction of peak load hours causes the linear model to overstate LOLE (Figure A.5). Due to this bias in the linear model, we use a nonlinear model in our main analysis.

\section{Step 3: Bootstrap residuals of the stationary model}

To account for uncertainty in the underlying process/model, we bootstrap the residuals of the stationary time series model, $\gamma_{t}$,Eq. (2). We bootstrap residuals by month, in 24-hour blocks. Bootstrapping by month allows us to account for heteroskedasticity in the residuals (Figure A.6); 
using 24-hour blocks allows us to account for time dependence in the residuals (Figure A.7). The resulting bootstrapped residuals are used in Step 7.

\section{Step 4: Forecast temperatures}

Because the next year's temperatures are uncertain, we develop temperature forecasts for 2010 based on historic NOAA weather data dating back to 1949 for D CA and PIT airports (NOAA 2014a) (years 1966 - 1972 were excluded due to missing data). We use hourly temperature, relative humidity, and wind speed data to calculate the average adjusted daily temperature ( $\left.\operatorname{Tadj} \operatorname{avg}_{D}\right)$ for D CA and PIT each day (Table 3, Equations (3) to (6)). We bootstrap days from this 60 year dataset, by month, in 10-day blocks. Bootstrapping by month allows us to account for the seasonal variations in temperature; using 10-day blocks allows us to account for time dependence in weather patterns that can last for several days (Figure A.8). Using 60 years of temperature data allows us to robustly account for extreme temperatures that may occur. We do not observe a secular trend in the NOAA temperature data. By using historic data, we do not account for the possibility of future climate-induced changes in temperature levels or volatility.

\section{Step 5: Forecast the stationary time series}

Once we have a model of the underlying stationary process (step 2), we use the model to predict the next year's stationary time series. This stationary time series excludes the effects of load growth. In this prediction, we use the temperature forecast developed in step 4.

\section{Step 6: Forecast load growth}

O ur forecast of growth in average load is based on PJM's 2009 forecast for 2010 load growth. We adjust the forecast to account for the historic accuracy of the Energy Information Agency's (EIA) load forecasts in the Annual Energy Outlook; insufficient data on PJM forecast accuracy is publically available. Between 1999 - 2008, EIA load growth forecasts had an average bias of $-0.3 \%$ and standard deviation of 1.9\% (EIA 2008). We assume forecast errors are normally distributed, 
and develop a distribution of possible load growth rates (Figure 3). We then sample growth rates from the resulting distribution. We assume load growth is linear throughout the year.

\section{Step 7: Forecast hourly load}

Finally, we sum the three components of our load forecast model: forecast load growth (step 6), the forecast stationary time series (step 5), and the residuals of the stationary time series regression (step 3). This allows us to separately account for the three sources of uncertainty: uncertain load growth, natural temperature variability, and uncertainty in the underlying model/ process. As all three components are probabilistic, we repeat the process many times to measure the uncertainty associated with each. The result is a probabilistic hourly forecast of load.

Once we have developed probabilistic hourly load forecasts for each zone, we sum these forecasts to find the total load forecast for PJM. We repeat the entire process 5,000 times to develop a probabilistic forecast of hourly PJM load in 2010.

\subsection{Supply forecast}

We next forecast the total capacity available at each hour. Total available capacity is the summed capacity of all online dispatchable plants, demand response, import capacity, and firm wind capacity. We use data from the 2010 PJM Form EIA-411 to identify each dispatchable plant's summer and winter capacity, as cleared in the capacity auction (PJM 2010b). We therefore assume the system operator has perfect information as to what generators will be available for the forecast year. We simulate the online status of each PJM generator, taking into consideration forced outages, planned outages, and maintenance outages. We simulate total capacity available for each of the 8760 hours of the year, and repeat the simulation 5,000 times to get a distribution of capacity available at each hour. We do not model other supply-side actions PJM can take to mitigate outage risks, such as voltage reductions. 
We first schedule planned outages and maintenance outages for all plants. These outages are scheduled such that the likelihood of a supply shortage is minimized. As such, the majority of outages are scheduled during the spring and fall. NERC's G enerating Availability D ata System (GADS) provides data on the average number of planned outage hours and maintenance outage hours for plants, aggregated by plant type and size (NERC 2014). We find that these outages can be scheduled with minimal effect on LO LE. We schedule each plant's planned outages and maintenance outages with the following process:

1. Find the total planned outage hours $(\mathrm{POH})$ and forced outage hours $(\mathrm{FOH})$ for each plant.

2. Divide plants into two categories: peaking plants and non-peaking plants. We identify peaking generators as natural gas combustion turbines smaller than $100 \mathrm{MW}$ and oil generators.

3. Schedule peaking outages such that the total offline capacity is roughly equal for all hours of the year. Each plant is assumed to undergo one outage, of duration $\mathrm{POH}+\mathrm{FOH}$. $\sim 1.7 \mathrm{GW}$ of peaking capacity is scheduled offline each hour.

4. Schedule non-peaking outages to occur during the spring (March, April, May) and fall (September, O ctober, November). Each plant is assumed to undergo one outage, of duration $\mathrm{POH}+\mathrm{FOH} . \sim 35 \mathrm{GW}$ of non-peaking capacity is scheduled offline each spring and fall hour.

By scheduling outages in this manner, we minimize the likelihood of a supply shortage. We also mimic the actual scheduling of outages in PJM, in which baseload coal and combined cycle plants are primarily offline during the spring and fall, and combustion turbines are offline throughout the year (Figure A.1).

We next model forced outages. Forced outages are caused by unforeseen technical problems, occur randomly throughout the year, and have an uncertain duration. We model plant forced outages as a two-stage discrete Markov chain (Billinton et al. 1973). Figure 4 illustrates this process. At each time period $t$, if the plant is online there is probability $P_{1,1}$ that it remains on at period $t+1$ and probability $\mathrm{P}_{1,0}$ that is fails. If the plant is offline, it remains off with probability $\mathrm{P}_{0,0}$ and is 
repaired with probability $\mathrm{P}_{0,1}$. Accounting for the duration of outages increases the uncertainty of how much capacity is available at each hour. We simulate each plant's forced outages over one year (8760 hours), then sum the total online capacity of all PJM plants. We assume that each plant's transition probabilities are constant throughout the year.

GADS provides data on the mean number of forced outages, and PJM provides data on plant equivalent demand forced outage rates (EFORd) (PJM 2014b). We use these data to calculate the transition probabilities with Equations (7) through (11) (Table 4). EFORd is defined as "the probability that a generating unit will fail, either partially or totally, to perform when it is needed to operate" (PJM 2011a). All data are aggregated by plant type and size.

We estimate the available D R capacity and net import capacity based on the results of the capacity auctions (PJM 2009) (Table 5). Each auction covers the period of June 1 of the first year to May 31 of the second year. We derate D R capacity by $5 \%$, as is PJM's practice to account for D R that does not respond to PJM requests (PJM 2010a). Firm wind capacity is assumed by PJM to be 13\% of nameplate capacity (PJM 2009); for both 2009 and 2010, firm wind capacity was 40 MW.

\subsection{Outage forecast}

We assume here that an outage occurs when total load exceeds total available capacity. Using the procedures outlined above, we develop yearly forecasts of hourly load and available capacity. We then subtract the hourly load forecast from the hourly forecast of available capacity to identify if an outage has occurred, Equation (12) (Table 6). We calculate UE and LO LH with Equations (13) and (14) to find the number of outages per ten simulated years (Table 6). LO LE is calculated in a similar manner as LO LH, but all consecutive outage hours are counted as one outage event. We repeat the process 10,000 times to develop distributions of LOLE, UE, and LOLH. We repeat the entire process, varying the amount of installed capacity in order to see how reliability metrics change 
versus reserve margin. To vary capacity, we add or subtract a constant amount from each hour's available capacity.

O ur modeling does not consider the effect of transmission constraints on resource adequacy. In the 2009/ 2010 auction, PJM found inflows were constrained to the Eastern Mid-Atlantic Area Council (EMAAC) and southwestern MAAC. Additional capacity was procured in these regions, resulting in higher capacity prices in these regions (PJM 2008). In the 2010/ 2011 auction, PJM found no transmission constraints, and capacity prices were equal throughout the interconnection. We also ignore any operating or synchronous reserve requirements.

PJM's Base Residual Auction is held in May, three years prior to the delivery year. By conducting the auction three years in advance, PJM seeks to reduce uncertainty for market participants. Each year after the Base Residual Auction, PJM conducts Incremental Auctions to account for changes in market conditions. O ur analysis simulates the last Incremental Auction, one year in advance of the delivery date. As such, we use data from 2009 and earlier to develop the 2010 forecast. In principle, our methods could be used to simulate the Base Residual Auction, but would need to be adjusted to account for the increased uncertainty in available capacity and load three years in advance.

\subsection{Economically Optimal Reserve Margin}

We analyze the level of capacity procurement that minimizes long-run total system costs. We use PJM generator data and load data from 2010 in this analysis. We consider costs from four sources: costs on the capacity market, energy market, outage costs, and reserve shortage costs. In 2010, PJM's reserve margin (installed capacity) was 20.5\%. We quantify total system costs for reserve margins of $10 \%-20 \%$. These methods are similar to those used by other studies of the economically optimal reserve margin (Newell et al. 2014, Pfeifenberger et al. 2013). 
The consequences of reducing PJM's reserve margin depend greatly on the type of capacity that is no longer procured (retired). Procuring less capacity would force the retirement of plants with the highest capacity market bids. However, individual capacity market bids are not publically available, and therefore we cannot know which plants would retire. If baseload capacity retired, costs on the energy market increase significantly. If peaking capacity retired, energy market costs would be unchanged.

We assume procuring less capacity would force the retirement of coal plants that are expensive to operate. PJM has identified $11 \mathrm{GW}$ of coal capacity "at high risk" of retirement, and an additional 14 GW of coal capacity "at some risk" of retirement (PJM, 2011b). These plants are smaller than $400 \mathrm{MW}$ and older than 40 years. However, it is possible that lower reserve margins might force other types of capacity to retire. We therefore bound our analysis with two scenarios: only baseload plants retire, and only peaking plants retire.

We evaluate four types of system costs: costs on the capacity market, energy market, outage costs, and reserve shortage costs. Total system costs are approximated as the sum of these four cost categories. We exclude several other types of costs, including costs on regulation markets, emergency import costs, and demand response costs. Although these categories are small relative to the costs considered here (Newell et al., 2014), future work could consider these and other system costs.

We quantify energy market costs with a reduced form supply curve dispatch model. Energy market costs are calculated as the sum of generator fuel and variable operation and maintenance costs throughout the year. We assume generators are dispatched each hour in order of least cost. We do not capture constraints that can lead to out-of-merit-order dispatch, such as transmission constraints and generator ramping constraints. We use 2010 hourly load data and generator capacity 
data from PJM (PJM 2014a, PJM 2010b) to estimate energy costs. We derate each plant's capacity by the forced outage rate (PJM 2011a). D elivered fuel cost data is from (EIA, 2014b) and (Lazard, 2010). Variable operation and maintenance costs are from Lazard (2010). Plant heat rates are from eGRID (EPA, 2014). As shown in Figure 5, the baseline scenario retires the most expensive coal plants to operate. For the sensitivity analysis, we retire plants with the lowest operating costs (baseload) and highest operating costs (peakers).

We estimate long run capacity costs as the total cost of building and operating a new natural gas combustion turbine (NGCT) plant, net expected revenues on the energy market (net CONE). We approximate this quantity, known as the net cost of new entry (net CO NE), as $\$ 100 / \mathrm{kW}$-yr based on findings of existing studies (Spees et al. 2011).

We assume a reserve shortage occurs in any hour of the year $\mathrm{H}$ when hourly load is high enough to force PJM to draw from their day ahead schedule reserves (DASR) (Eq. 15). Shortages are valued at PJM's current price cap of $\$ 2,700$ / MWh (PJM, 2014e). Hourly 2010 D ASR data is from PJM (2014f).

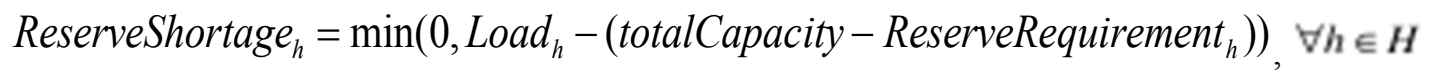

The cost of an outage is the total unserved energy (UE), multiplied by the value of lost load (VoLL) of consumers. We multiply the simulated UE values by an assumed VoLL to approximate the total cost of outages. We assume a VoLL of $\$ 15 / \mathrm{kWh}$, based on the estimated costs of a one hour interruption for medium/ large commercial and industrial consumers (Sullivan, 2009). 


\subsection{Correlated outages}

Next, we evaluate the risk posed by low probability but high impact events that can force the correlated failure of multiple generators simultaneously. Traditional resource adequacy planning does not account for such risks. We do not attempt to quantify the probability of such correlated failures occurring. Rather, we vary the likelihood of correlated failures and test how resource adequacy metrics change.

First we test how LO LE, LO LH, and UE would vary if all $50 \mathrm{GW}$ of PJM natural gas generators were subject to the risk of a natural gas supply disruption. We test the risk posed by supply disruptions that could occur at any point during the year, and we test the risk for supply disruptions that only occur during winter months (D ecember - February). We model the hourly risk of a fuel supply shortage as $\mathrm{P}_{\mathrm{FS}}$. We then evaluate each winter hour if a supply shortage occurs with Equation (16) (Table 7). We assume the risk of a supply shortage is uniform throughout the winter. If a supply shortage occurs, the probability of each individual generator failing is $\mathrm{P}_{\text {outage }} \mathrm{FS}_{\text {s }}$ Eq. (17) (Table 7); if no supply shortage occurs, we adjust the probability of an independent failure occurring such that the overall risk of failure is equal to the case in which all outages are independent, Eq. (10). We therefore do not change the probability of an outage occurring. Rather, we adjust the fraction of outages due to a supply shortage versus an independent failure. Because data on the frequency and severity of correlated outages is not publically available, we test the sensitivity to each parameter. First, we vary the hourly probability of a supply shortage such that the likelihood of a disruption occurring varies from twice per year/ winter to once every 5 years/ winters, assuming that all gas generators fail if a shortage occurs $\left(\mathrm{P}_{\text {outage } \mathrm{FS}}=1\right)$.

Second, we test how seasonal variations in plant reliability may affect resource adequacy. As evidenced by the 2014 Polar Vortex, extreme cold can cause outages at all types of generators. Coal, 
gas, and nuclear plants were all offline during the Polar Vortex due to reasons including mechanical failures, frozen pipes, frozen coal piles, and gas supply disruptions (PJM, 2014c). We test how system reliability change would change if plant EFORd were modeled as sensitive to ambient temperature. We model all plants as 50\% less likely than baseline to be forced offline during the warmest 6 months (April - September) and 50\% more likely to be forced offline in the coolest 6 months (O ctober - March).

Third, we test the risk posed by all PJM nuclear generators shutting down simultaneously, as occurred in Japan due to regulatory intervention after the Fukushima D aiichi disaster. We assume the risk of such a correlated failures is constant throughout the year, and vary the likelihood of such an event occurring from once every 10 years to once every 50 years. We assume that such a regulatory intervention would force generators to be offline for an average duration of six months $\left(\mathrm{P}_{01}=1 / 4330, \mathrm{P}_{00}=1-1 / 4330\right)$.

\section{Results}

Table A.1 shows accuracy statistics of the load model, both in the training data for 2000-2009 and test data when predicting 2010 load. The test error is the model's prediction error when given actual 2010 temperatures and load growth; it therefore ignores uncertainty in temperature and load

growth. Normalized root-mean-square error (NRMSE) controls for the size of the PJM region, Eq. (18). Table A.2 shows detailed regression results for the "PJM Classic" region.

$$
N R M S E=\frac{R M S E}{\operatorname{load}_{\max }-\operatorname{load}_{\min }}
$$

The model's accuracy could certainly be improved further. Including weather data from more points within PJM would likely have the greatest effect on model accuracy. Our model uses weather 
data from Reagan National and Pittsburgh International Airports; PJM's long-term load forecasting model uses temperature data from 24 airports (PJM 2013).

\subsection{Reliability metrics}

Figure 6 shows simulated 2010 LO LE for reserve margins of 10\% to 25\%. The expected value of our 2010 simulation closely matches that of PJM's 2013 simulation (data on PJM's 2010 simulation is not available, but the results of the simulation have changed very little over time). In 2010, PJM found a 15.5\% reserve margin was necessary to meet the 0.1 LOLE standard (PJM 2010a); we find a 15.5\% reserve margin would have resulted in an LO LE of 0.8 events per year. O ur simulation's $90 \%$ confidence interval ranges from zero to three events per ten years at $15.5 \%$ reserve margin.

The actual 2010 reserve margin was 20.5\% (164 GW), as PJM procured more capacity than was needed on the capacity market (PJM 2008) ${ }^{2}$. We find that a 20.5\% reserve margin corresponds to an expected LOLE of 0.12 events per year, and achieves the 0.1 LO LE standard with $90 \%$ confidence.

Figure 7 shows simulated 2010 unserved energy versus reserve margin. At a 15.5\% reserve margin, the expected UE is $1.1 \mathrm{GWh}$ per year, or $0.00015 \%$ of actual 2010 load. The $90 \%$ confidence interval ranges from $0 \mathrm{GWh}$ per year to $6.1 \mathrm{GWh}$ per year $(0.0000 \%-0.0008 \%$ of load unserved, respectively). UE becomes increasingly uncertain at lower reserve margins. Expected LOLH is 3.4, with a $90 \%$ confidence range of 0 to 14 .

We find that PJM's target 2010 reserve margin of $15.5 \%$ was sufficient to meet the $0.1 \mathrm{LOLE}$ standard. Switching to either the 2.4 LO LH standard or the $0.001 \%$ UE standard could reduce reserve margins to $10 \%$ (Table 8). Procuring additional capacity such that the realized reserve

${ }^{2}$ Generation offered + fixed resource requirement (FRR) commitments - generation offered but not accepted 
margin was 20.5\% implies PJM wishes to meet the 0.1 LO LE standard with 90\% confidence. PJM could meet the $2.4 \mathrm{LO} \mathrm{LH}$ standard and $0.001 \%$ UE standard with 90\% confidence at reserve margins of $13 \%$. Requiring that the reliability metric be met with $95 \%$ or $99 \%$ confidence would further increase reserve margin requirements.

\subsection{Economically Optimal Reserve Margin}

We estimate that PJM's long run, economically optimal reserve margin is $13 \%-15 \%$. System costs change by less than $\$ 100$ million within this range, or less than $1 \%$ of the total $\$ 28$ billion in estimated system costs. As shown in Figure 8, costs associated with outages and reserve shortages become more significant as reserve margins fall below $14 \%$. Above $14 \%$, capacity market costs increase significantly. Because this range includes the 13\% targets needed to meet the $2.4 \mathrm{LO} \mathrm{LH}$ standard and $0.001 \%$ UE standard with 90\% confidence, we conclude that either of these standards could be considered efficient. However, maintaining PJM's realized 2010 reserve margin of 20.5\% would increase annual system costs by $\$ 600$ million annually over a $\$ 15$ billion per year baseline in the long run.

System costs are very sensitive to the type of capacity that is retired when PJM procures less capacity. As shown in Figure 9, if the retired capacity is baseload plants, total system costs increase significantly as reserve margins decrease. If retired capacity are either expensive coal plants or peaker plants, system costs are minimized for reserve margins of 13\% - 15\%.

We find that outage costs are small in the long run, as the expected unserved energy is small. We therefore conclude that the economically optimal reserve margin is insensitive to VoLL, here assumed to be $\$ 15 / \mathrm{kWh}$.

O ur results are similar to those of other, similar studies (Newell et al., 2014 and Pfeifenberger et al. 2013). Newell et al. found that the economically optimal reserve margin in the ERCOT system is 
$10.2 \%$, lower than the reserve margin needed to meet the 0.1 LOLE standard. Similar to our results, the study found that system costs do not vary significantly for reserve margins of $8 \%-14 \%$ but does note that there is more uncertainty in system costs at lower reserve margins. Consistent with these studies, we find that the economically optimal reserve margin in PJM is lower than the reserve margin needed to meet the 0.1 LOLE standard. Our results for PJM add to a growing body of literature suggesting that for a variety of systems the 0.1 LOLE may result in higher capacity procurements than are economically optimal in the long run.

\subsection{Distribution of outage size}

We find that there is extreme variation in the amount of load shed during outages. As shown in Figure 10, the distribution of unserved energy resulting from an outage is extremely fat tailed. At a $15.5 \%$ reserve margin, the mean outage is $15 \mathrm{GWh}$, but outages range from $0 \mathrm{GWh}$ to $110 \mathrm{GWh}$ (Table 9). The top 10\% largest outages account for half of total unserved energy, and the top $1 \%$ of outages account for $10 \%$ of total unserved energy. The risk of a very large outage becomes more pronounced at lower reserve margins.

\subsection{Model form uncertainty}

Load in PJM is highly sensitive to temperature, and accurately modeling this relationship is important for accurately calculating LO LE. We used a nonparametric, additive model to account for the relationship between load and temperature. We also tested a linear model to account for the relationship. The linear model divided days into heating degree days (HDD ) and cooling degree days (CDD ). D etails can be found in Appendix A. We find that the linear model significantly overpredicts load at high temperature hours, which increases the modeled probability of outages relative to the nonparametric, additive model (Figure A.5). 
In our regressions, we hold each plant's forced outage rate (EFO Rd) constant throughout the year. Finally, we test the effects on LOLE of EFORd being sensitive to ambient temperature, with plants being $50 \%$ less likely to be forced offline during summer the warmest 6 months (April September) and 50\% more likely to be forced offline in the coolest 6 months (O ctober - March).

\subsection{Correlated failures}

We find that natural gas supply disruptions have the potential to increase the risk of a supply shortage, assuming such outages force a large percentage of PJM's gas generators offline at once. If a supply disruption that forces all of PJM's gas generators offline were to occur on average once every fifth year, the expected UE would double (Figure 11). Such supply disruptions can significantly increase the maximum size of supply shortages (Figure A.9). Supply shortages that occur only during winter months do not have a significant effect on reliability.

We find that winter resource adequacy risks may be understated if plant reliability varies seasonally. If plant outage rates were 50\% higher than baseline in winter months and $50 \%$ lower in summer months, system LOLE would more than double (Figure 12). However, our gas supply shortage analysis shows that winter gas supply disruptions alone do not significantly affect resource adequacy. As occurred during the 2014 Polar Vortex, mechanical and fuel supply issues at coal and nuclear generators during extremely cold days are also a significant contributor to winter resource adequacy issues.

We find that nuclear power supply disruptions also have the potential to increase the risk of a supply shortage. The likelihood of a regulatory action that forces all PJM nuclear generators offline simultaneously is unknown. However, we find that if such an action were to occur once every 50 years and force all nuclear generators offline for an average of 6 months, expected UE would quadruple (Figure 13). 


\section{Discussion}

Using our probabilistic regression method, we find the 2010 reserve margin target of $15.5 \%$ was sufficient to meet the mandated 0.1 LOLE standard. PJM procured $7 \mathrm{GW}$ more capacity than needed to meet the $15.5 \%$ target, making the realized reserve margin $20.5 \%$. By procuring more capacity than needed, PJM met the 0.1 LO LE standard with $90 \%$ confidence. This is due to PJM's policy to procure more capacity than needed if the capacity can be procured at a cost less than the net cost of new entry of a natural gas combustion turbine ( \$270/ MW-day) (PJM 2008, Spees et al. 2011).

Switching from the 0.1 LOLE standard to either the 2.4 LOLH or $0.001 \%$ UE standard would have reduced PJM's 20.5\% reserve margin in 2010. A 13\% reserve margin would have been sufficient to meet the $0.001 \%$ UE standard or the $2.4 \mathrm{LOLH}$ standard with $90 \%$ confidence. This represents an $11 \mathrm{GW}$ reduction in capacity procurement, while still maintaining levels of reliability accepted by other systems. If PJM were to switch to either standard, the $11 \mathrm{GW}$ of coal capacity "at high risk" of retirement could be retired without needing to be replaced. In addition, we find that a reserve margin of 13\% - 15\% minimizes total system costs.

PJM's resource adequacy modeling assumes that generator outages are independent. We find that correlated outages among generators could significantly increase outage risk, and cause PJM to underestimate this risk. Evidence suggests that correlated outages do occur with some regularity; winter storms in January 2014 led to $19 \mathrm{GW}$ of natural gas plants and $21 \mathrm{GW}$ of other capacity simultaneously experiencing forced outages (PJM 2014c). Although winter supply risks have recently been the focus of much attention, we demonstrate that other types of correlated failures may also pose risks. For example, the risk of a forced shutdown of all nuclear generators, while unlikely, could significantly affect reliability. 
System operators should be aware that the risk posed by supply shortages is primarily due to extremely severe, but infrequent outages. O ur simulations show that the largest 10\% of supply shortages are responsible for $50 \%$ of unserved energy. Taking into account the possibility of correlated generator outages further exacerbates this risk. The risk of very large outages increases at low reserve margins, suggesting that PJM's policy of over-procuring capacity may be justified.

\section{Conclusions ANd Policy Implications}

Improved understanding of supply shortage risks is increasingly important in today's era of declining reserve margins and coal retirements. Several ISO s, including PJM, have begun to take steps to address these concerns. PJM recently submitted a proposal to the Federal Energy Regulatory Commission (FERC) to establish a Capacity Performance product (PJM 2014d) that would provide stronger incentives for generators to be available during peak-demand periods.

Resource adequacy modeling is difficult due to the inherent uncertainty intohe likelihood and magnitude of supply shortages. The difficult of resource adequacy modeling is further complicated by the myriad of metrics with which reliability can be measured. NERC recommends that system operators adopt a reliability metric based on unserved energy. We agree. The LO LE metric is flawed, in that it measures only the probability of an outage occurring and ignores both the severity and duration of outages. O ur modeling shows that the severity and duration of outage events vary greatly (Table 9), undermining the usefulness of the LOLE metric. O ur results also indicate that the 0.1 LO LE standard results in higher reserve margins than other commonly used metrics, such as 0.001\% UE or 2.4 LOLH. In 2010, switching from the LO LE standard to a UE or LO LH standard would have allowed PJM to reduce reserve margins from $20.5 \%$ to $13 \%$, while maintaining current risk preferences and levels of reliability accepted by other systems. Because supply shortages could cause political fallout both regionally and for system operators, we recommend that ISO s work with 
NERC and stakeholders to identify both the appropriate UE target and the risk tolerance of PJM participants.

Basing capacity decisions on traditional reliability standards ignores the cost effectiveness of carrying excess capacity. Achieving a very high reliability standard may be possible, but extremely costly. Recently, system operators such as ERCOT have begun to incorporate the cost effectiveness metrics into decision making processes (Newell et al. 2014). A study commissioned by the Public Utility Commission of Texas found that the economically optimal reserve margin in the ERCOT system is $10.2 \%$ (Newell et al. 2014). This is lower than the $14.1 \%$ reserve margin the study found was needed to meet the 0.1 LOLE study, but higher than the $9.1 \%$ reserve margin needed to meet 2.4 LO LH standard and the $9.4 \%$ reserve margin needed to meet the $0.001 \%$ UE standard. We find that a reserve margin of 13\% - 15\% would have minimized total long-term system costs in PJM.

System planners should consider the risks posed by events that can cause correlated outages among generators. Many potential systemic risks exist, including extreme weather, natural disasters, and unforeseeable and sudden regulatory actions that force many plants offline (a risk that was exposed when the Japanese nuclear fleet was shutdown after the Fukushima disaster). Resource adequacy models typically assume plant failures are uncorrelated with one another and therefore ignore systemic risks. We demonstrate that systemic risks may pose a real threat to resource adequacy (see Section 3.6).

We recommend four specific improvements to the resource adequacy modeling and decision making process.

First, our modeling supports NERC's recommendation that systems move from a LOLE metric of resource adequacy to the unserved energy (UE) metric, which more accurately quantifies the risks of supply shortages. We show that the 0.1 LO LE standard is also conservative compared to the 
0.001\% UE standard. We find that in 2010 PJM could have reduced reserve margins by 7.5\%, or 11 GW, and achieved the $0.001 \%$ UE standard used by other systems. System operators should work with stakeholders and NERC to identify what unserved energy targets are appropriate.

Second, we recommend that system operators consider the system cost consequences of resource adequacy decisions. We recommend that PJM and other system operators supplement their resource adequacy modeling and decision making by calculating the economically optimal reserve margin that minimizes total system costs. The results of this analysis should be conveyed to stakeholders and inform capacity procurement decisions alongside traditional reliability metrics.

Third, we recommend further research into systemic risks that can cause many generators to fail at the same time, especially low probability, high impacts risks that are difficult to quantify with retrospective analyses. O ur analysis suggests such systemic risks have the potential to negatively affect reliability. These risks are not accounted for in traditional system planning. Additional research is needed into the potential causes of correlated outages, their likelihood, and potential severity. If systemic risks are found to be significant when added to resource adequacy models, systems may need to increase reserve margins.

Finally, the resource adequacy modeling and decision making process should be made more transparent. The methods used should be made publically available. To the extent possible, data and results should also be made publically available. Models should be run under a variety of scenarios and assumptions to test for robustness. The limitations of the modeling should be acknowledged and conveyed to stakeholders and the public.

\section{ACKNOWLEDGEMENTS}

The authors acknowledge support from the D oris D uke Charitable Foundation, the Richard King Mellon Foundation, The Heinz Endowments, and the Carnegie Mellon Electricity Industry 
Center. This research was also supported in part by the Climate and Energy D ecision Making (CED M) center, created through a cooperative agreement between the National Science Foundation (SE S-0949710) and Carnegie Mellon University. This research was also supported by the U.S. D epartment of Energy's National Energy Technology Laboratory. The authors thank Kathleen Spees for helpful discussions. The views expressed in this paper are strictly those of the authors and do not necessarily state or reflect the views of Carnegie Mellon University or The Brattle Group, Inc. 


\section{Appendix A}

\section{Detailed Regression Results}

Table A.2 provides detailed regression results for the PJM Classic region. We find that the significant results have the expected sign in most cases. For example, signs are negative for holidays, reflecting that load are lower on these days. Signs are also negative for low-load hours during the night and positive for high-load hours during the day and evening.

\section{Linear model results}

We use a non-parametric, additive model to account for the relationship between adjusted average daily temperature and hourly load (see Methods - Step 2). However, we also investigated the potential of using a linear model to account for the relationship. As discussed below, we found that using a linear fit worked well for the majority of hours, but considerably over-predicted loads during high temperature days. This over prediction led to the linear model over-estimating the probability of a supply shortage.

The linear model we used in the second step considered the maximum and minimum daily temperature, as shown in Eq. (A.1). We divided days into heating degree days (HDD) and cooling degree days (CDD), as is common in literature (A.2). The split temperature between HDD / CD D was set to minimize model error: for Tmax terms, the temperature was $20.6^{\circ} \mathrm{C}$. For Tmin terms, temperature was $7.2^{\circ} \mathrm{C}$. We then used a linear and quadratic term for both HDD and CDD temperatures in the regression (A.3).$$
\beta_{t}=\gamma_{1} \text { weekday }+\gamma_{2}(\text { hour*month })+\gamma_{3} \text { holidays }+\gamma_{4} \text { Tmax. HDD }+\gamma_{5} \text { Tmax.CDD }+\gamma_{6}
$$$$
\text { Tmin.HDD }+\gamma_{7} \text { Tmin. } C D D+\gamma_{8} \operatorname{Tmax} . H D D^{2}+\gamma_{9} \operatorname{Tmax} . C D D^{2}+\gamma_{10} \text { Tmin.HDD } D^{2}+\gamma_{11}
$$ 
Tmin.CDD $D^{2}+\gamma_{12}\left(\right.$ daylightHours ${ }^{*}$ month $)+\gamma_{t}$

\section{REFERENCES}

Billington, R., Ringlee, R., Wood, A., 1973. Power-System Reliability Calculations. MIT Press.

Bresler, S., PJM, 2012. Personal communication.

Eastern Interconnection States' Planning Council (EISPC), 2013. The Economic Ramifications of Resource Adequacy White Paper. Available at

<http:/ / www.naruc.org/ grants/ D ocuments/ E conomics\%20of\%20Resource\%20Adequacy\%20WhitePaper Astrape_Final.pdf>. (accessed September 2014).

Energy Information Agency (EIA), 2008. Annual Energy O utlook reports, 1999 - 2008. Available at <http:/ / www.eia.gov/ forecasts/ aeo/ archive.cfm>. Accessed August 2014.

Energy Information Agency (EIA), 2014. Annual Energy Outlook 2014 Early Release. Available at: <http:/ / www.eia.gov/ forecasts/ aeo/ er/ index.cfm>. (accessed July 2014).

Energy Information Agency (EIA), 2014b. Electricity D ata Browser. <http:/ / www.eia.gov/ electricity/ data/ browser> (accessed August 2014).

Hagan, M. T., Behr, S. M., 1987. The time series approach to short term load forecasting. Power Systems, IEEE Transactions on, 2(3), 785-791.

Hastie, T, 2013. Package 'gam' documentation. Available at < http:// cran.rproject.org/ web/ packages/ gam/ gam.pdf>. Accessed January 2015.

Hines, P., Apt, J., Talukdar, S., 2009. Large blackouts in North America: Historical trends and policy implications. Energy Policy, 37(12), 5249-5259. 
Hippert, H. S., Pedreira, C. E., \& Souza, R. C., 2001. Neural networks for short-term load forecasting: A review and evaluation. Power Systems, IE E E Transactions on, 16(1), 44-55.

Joskow, P., 2006. Competitive electricity markets and investment in new generating capacity. AEIBrookings Joint Center Working Paper, (06-14).

Joskow, P., 2008. Capacity payments in imperfect electricity markets: Need and design. U tilities Policy, 16(3), 159-170.

Lazard. (2010). Levelized Cost of Energy Analysis - Version 4.0. < http:/ / webapp.psc.state.md.us/ intranet/ casenum/ NewIndex3 VOpenFile.cfm?filepath=C:\%5CCasenum\%5 $\underline{\text { C9200- }}$ 9299\%5C9214\%5CItem 119\%5C\%5CSierra\%20Club\%20and\%20CCAN_Case\%209214_Supplemental\%20 Exhibits\%20to\%20Comments\%5CLAZARD\%20LCOE\%206-12-10.pdf>. Accessed August 2015.

Newell, S. A., Spees, K., Pfeifenberger, J., Karkatsouli, I., 2014. Estimating the Economically Optimal Reserve Margin in ERCOT. Prepared for the Public Utility Commission of Texas. Available at <http:/ / brattle.com/ system/ news/ pdfs/ 000/ 000/ 613/ original/ Estimating_the_Economically_Optimal_Re serve_Margin_in_ERCOT.pdf?1391445083>. Accessed November 2014.

North American Electric Reliability Corporation (NERC), 2010. Final Report on Methodologies and Metrics - September and D ecember, 2010 with Approvals and Revisions. Available at <http:/ / www.nerc.com/ comm/ PC/ Reliability\%20Assessment\%20Subcommittee\%20RAS\%20D L/ GTRPM TF_Meth__Metrics_Report_final_w\%20_PC_approvals_revisions_12\%2008\%2010.pdf>. (accessed July 2014).

North American Electric Reliability Corporation (NERC), 2014. G enerator Availability D ata System. Available at <http:/ / www.nerc.com/ pa/ RAPA/ gads/ Pages/ default.aspx>. Accessed August 2014. 
Pfeifenberger, J., Spees, K., Carden, K., Wintermantel, N. (2013). Resource Adequacy Requirements: Reliability and Economic Implications. Available at < https:/ / www.ferc.gov/ legal/ staff-reports/ 2014/ 0207-14-consultant-report.pdf>. (accessed September 2014).

PJM Interconnection, 2003. PJM Generation Adequacy Analysis: Technical Methods. Available at <http:/ / www.pjm.com/ / media/ etools/ oasis/ references/ whitepaper-sections-12.ashx>. (accessed September 2014).

PJM Interconnection, 2008. 2010/ 2011 RPM Base Residual Auction Results. Available at <http:/ / www.pjm.com/ / media/ markets-ops/ rpm/ rpm-auction-info/ 20080201-2010-2011-brareport.ashx>. Accessed July 2014.

PJM Interconnection, 2009. 2012/ 2013 RPM Base Residual Auction Results. Available at <http:/ / www.pjm.com/ / media/ markets-ops/ rpm/ rpm-auction-info/ 2012-13-base-residual-auctionreport-document-pdf.ashx>. Accessed June 2014.

PJM Interconnection, 2010a. 2010 PJM Reserve Requirement Study. Available at <http:/ / www.pjm.com/ / media/ documents/ reports/ 2010-pjm-reserve-requirement-study.ashx>. Accessed July 2014.

PJM Interconnection, 2010b. EIA 411 Report. Available at <http:/ / www.pjm.com/ documents/ reports/ eia-reports.aspx> . Accessed June 2014.

PJM Interconnection, 2011a. 2010 State of the Market Report for PJM, Volume 2. Available at <http:/ / www.monitoringanalytics.com/ reports/ pjm_state_of_the_market/ 2010/ 2010-som-pjmvolume2.pdf>. (accessed September 2014).

PJM Interconnection, 2011b. Coal Capacity at Risk of Retirement in PJM: Potential Impacts of the Finalized EPA Cross State Air Pollution Rule and Proposed National Emissions Standards for Hazardous Air 
Pollutants. Available at <http:/ / pjm.com/ / media/ documents/ reports/ 20110826-coal-capacity-at-risk-forretirement.ashx>. (accessed July, 2014)

PJM Interconnection, 2013. PJM Manual 19: Load Forecasting and Analysis, Revision 23. Available at <http:/ / www.pjm.com/ / media/ documents/ manuals/ m19.ashx>. (accessed September 2014).

PJM Interconnection, 2014a. Historical Metered Load D ata. Available at <http:/ / www.pjm.com/ markets-and-operations/ ops-analysis/ historical-load-data.aspx>. Accessed June 2014.

PJM Interconnection, 2014b. PJM Monthly EFO Rd Data. Available at <http:/ / www.pjm.com/ markets-and-operations/ energy/ real-time/ historical-bid-data/ eford.aspx> . Accessed June 2014.

PJM Interconnection, 2014c. Analysis of O perational Events and Market Impacts D uring the January 2014 Cold Weather Events. Available at <http:/ / www.pjm.com/ / media/ documents/ reports/ 20140509analysis-of-operational-events-and-market-impacts-during-the-jan-2014-cold-weather-events.ashx> . Accessed November 2014.

PJM Interconnection, 2014d. Reforms to the Reliability Pricing Market ("RPM") and Related Rules in the PJM O pen Access Transmission Tariff ("Tariff") and Reliability Assurance Agreement Among Load Serving Entities ("RAA"). Submitted to FERC, D ocket No. ER15-623-000. Available at < http:/ / www.pjm.com/ / media/ documents/ ferc/ 2014-filings/ 20141212-er15-623-000.ashx>. Accessed January 2015.

PJM Interconnection, 2014e. Scarcity Pricing. Available at < $\underline{\text { http:// www.pjm.com/ / media/ about- }}$ pjm/ newsroom/ fact-sheets/ shortage-pricing-fact-sheet.ashx (2014)>. Accessed August 2014. 
PJM Interconnection, 2014f. D ay-A head Scheduling Reserve Preliminary Billing D ata. Available at <http:/ / www.pjm.com/ markets-and-operations/ market-settlements/ preliminary-billing-reports/ dsrpjm.aspx>. Accessed August 2014.

Spees, K., Newell, S. A., Carlton, R., Zhou, B., Pfeifenberger, J., 2011. Cost of New Entry Estimates For Combustion Turbine and Combined-Cycle Plants in PJM.

Spees, K., Newell, S., Pfeifenberger, J., 2013. Capacity Markets-Lessons Learned from the First D ecade. Economics of Energy \& Environmental Policy 2.2.

Sullivan, Michael J., 2009. Estimated Value of Service Reliability for Electric Utility Customers in the United States. Lawrence Berkeley National Laboratory. Available at < $\underline{\mathrm{http}}$ :/ / certs.lbl.gov/ pdf/ lbnl2132e.pdf> Accessed September 2014.

U.S. Environmental Protection Agency (EPA), 2014. http://www.epa.gov/cleanenergy/energyresources/egrid/index.html. Accessed Aug, 2014.

U.S. National O ceanic and Atmospheric Administration (NOAA), 2013. NWS Windchill Chart. Available at <http:/ / www.nws.noaa.gov/ os/ windchill/ index.shtml>. Accessed August 2014.

U.S. National O ceanic and Atmospheric Administration (NOAA), 2014a. National Climatic D ata Center website. Available at <http:/ / cdo.ncdc.noaa.gov/ pls/ plclimprod/ poemain.accessrouter?datasetabbv=D S3505>. Accessed June 2014.

U.S. National O ceanic and Atmospheric Administration (NOAA), 2014b. NWS Weather Service Heat Index. Available at <http:/ / nws.noaa.gov/ os/ heat/ index.shtml>. Accessed August 2014.

U.S. Naval O bservatory, 2012. D uration of D aylight/ D arkness Table for O ne Y ear. Available at <http:/ / aa.usno.navy.mil/ data/ docs/ D ur_O neY ear.php>. Accessed June 2014. 


\section{TABLES AND FIgURES}

Table 1. PJM Expansions, 1993 - 2010 (PJM 2014a)

\begin{tabular}{ll}
\hline Expansion & Date \\
\hline Rockland Energy & March 2002 \\
Allegheny Energy & April 2002 \\
Exelon - Commonwealth Edison & May 2004 \\
AEP & October 2004 \\
Dayton Power \& Light & October 2004 \\
Duquesne Light Co & January 2005 \\
Dominion Virginia & May 2005 \\
\hline
\end{tabular}
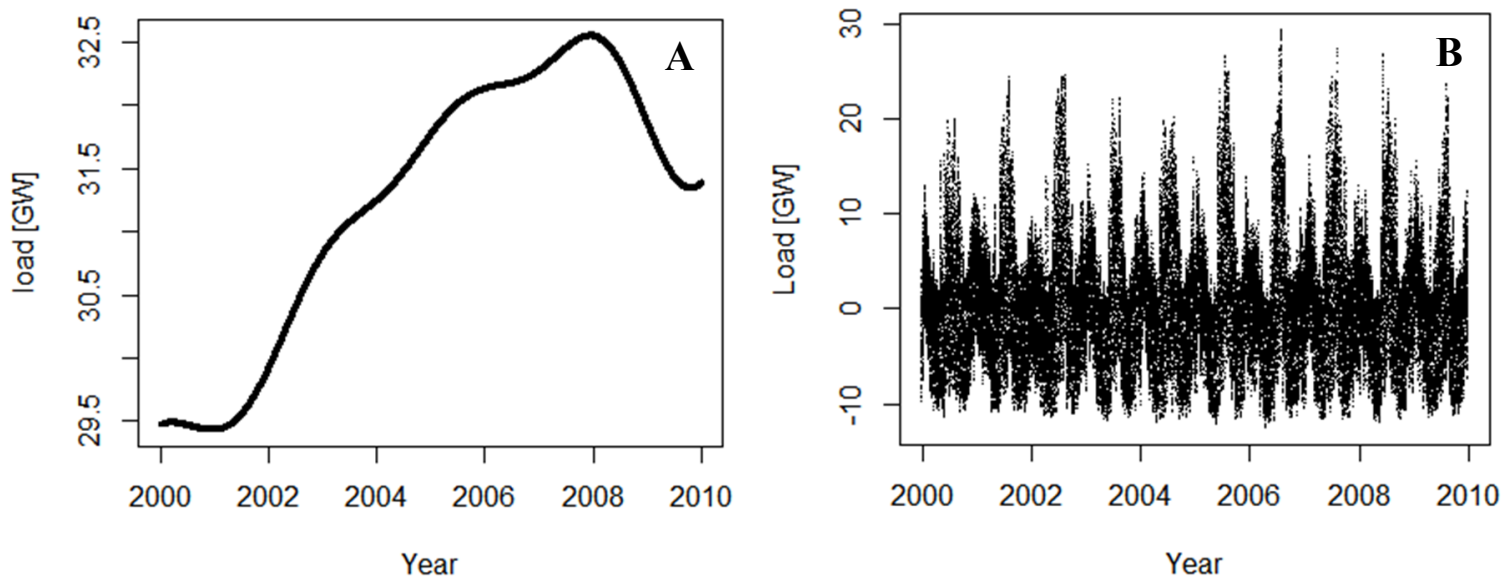

Figure 1. (A) Fitted long-term trend and (B) stationary hourly residuals, $\beta_{\mathrm{t}}$ for PJM Classic. Table 2. Weather station used for each zone's regression

\begin{tabular}{ll}
\hline Region & $\begin{array}{l}\text { Weather station } \\
\text { used }\end{array}$ \\
\hline PJM Classic & DCA \\
Rockland Energy & DCA \\
Allegheny Energy & DCA \\
Exelon - Commonwealth Edison & PIT \\
AEP & PIT \\
\hline
\end{tabular}




\begin{tabular}{ll}
\hline Dayton Power \& Light & PIT \\
Duquesne Light Co & PIT \\
Dominion Virginia & DCA \\
\hline
\end{tabular}

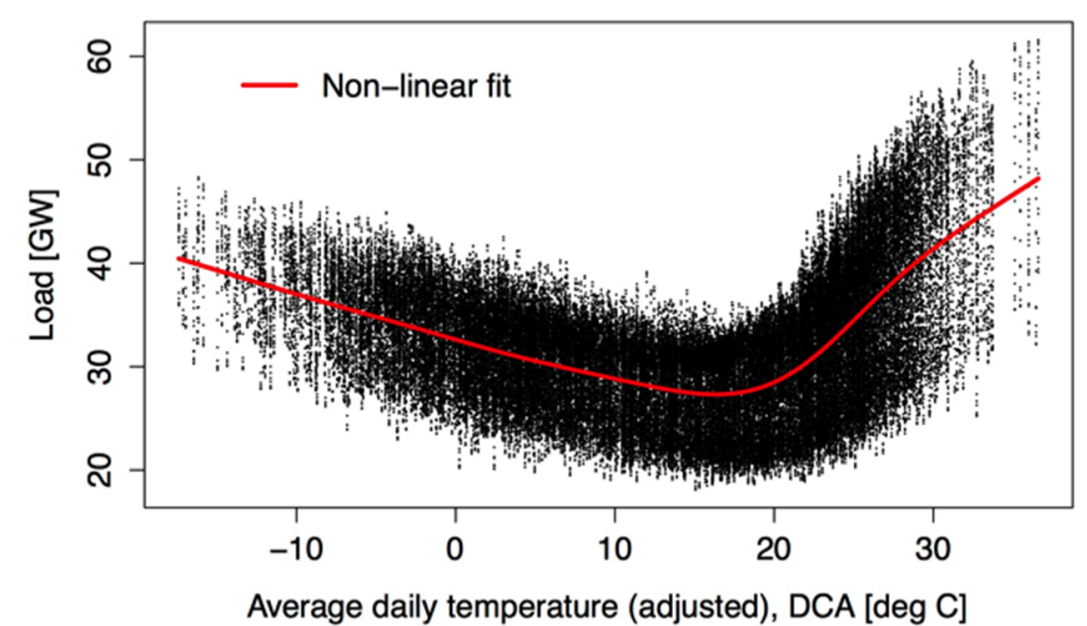

Figure 2. Relationship between hourly load in PJM Classic and adjusted average daily temperature at Reagan National Airport (DCA), 2000 - 2009. Because the relationship is highly nonlinear, we use a non-linear, additive model to account for temperature dependence.

\section{Table 3: Temperature calculations}

\begin{tabular}{|c|c|}
\hline $\begin{array}{l}\text { THI }=c_{1}+c_{2} T_{i}+c_{3} R_{i}+c_{4} T_{i} R_{i}+c_{5} T_{i}^{2}+c_{6} R_{i}^{2}+c_{7} T_{i}^{2} R_{i}+c_{8} T_{i} R_{i}^{2}+c_{9} T_{i}^{2} R_{i}^{2} \\
\mathrm{C}_{1}=-42.379 \\
\mathrm{C}_{2}=2.04091523 \\
\mathrm{C}_{3}=10.14333127 \\
\mathrm{C}_{4}=-0.22475541 \\
\mathrm{C}_{5}=-6.83783 \times 10^{-3} \\
\mathrm{C}_{6}=-5.481717 \times 10^{-2} \\
\mathrm{C}_{7}=1.22874 \times 10^{-3} \\
\mathrm{C}_{8}=8.5282 \times 10^{-4} \\
\mathrm{C}_{9}=-1.99 \times 10^{-6}\end{array}$ & (3) \\
\hline$W C I_{i}=35.74+0.6215 T_{i}-35.75 V_{i}^{0.16}+0.4275 T V_{i}^{0.16}$ & (4) \\
\hline Tadj $_{i}=\left\{\begin{array}{l}T H I_{i}, \quad \text { if } T_{i} \geq 80^{\circ} \mathrm{F} \text { and } R_{i} \geq 40 \% \\
W C I_{i}, \text { if } T_{i} \leq 50{ }^{\circ} \mathrm{F} \text { and } V_{i} \geq 3 \mathrm{mph} \\
T_{i}, \quad \text { otherwise }\end{array}\right.$ & (5) \\
\hline $\operatorname{Tadj} \operatorname{avg}_{D}=\operatorname{mean}\left(\operatorname{Tadj}_{i}\right), \quad \forall i \in D$ & (6) \\
\hline$i=$ hour of the day & \\
\hline
\end{tabular}


$D=$ day of the year

$T_{i}=$ hourly temperature $\left[{ }^{\circ} \mathrm{F}\right]$

$R_{i}=$ hourly relative humidity [percentage value between 0 and 100]

$V_{i}=$ hourly wind speed [mph]

$T H I_{i}=$ temperature humidity index $\left[{ }^{\circ} \mathrm{F}\right]$

$W C I_{i}=$ wind chill index $\left[{ }^{\circ} \mathrm{F}\right]$

$\operatorname{Tadj}_{i}=$ hourly adjusted temperature

$\operatorname{Tadj}, \operatorname{avg} D=$ daily average adjusted temperature $\left[{ }^{\circ} \mathrm{F}\right]$

WCI index equation from (NOAA 2013); THI index equation based on (NOAA 2014b). Although conversion equations are in English units, the remainder of our analysis uses Celsius.

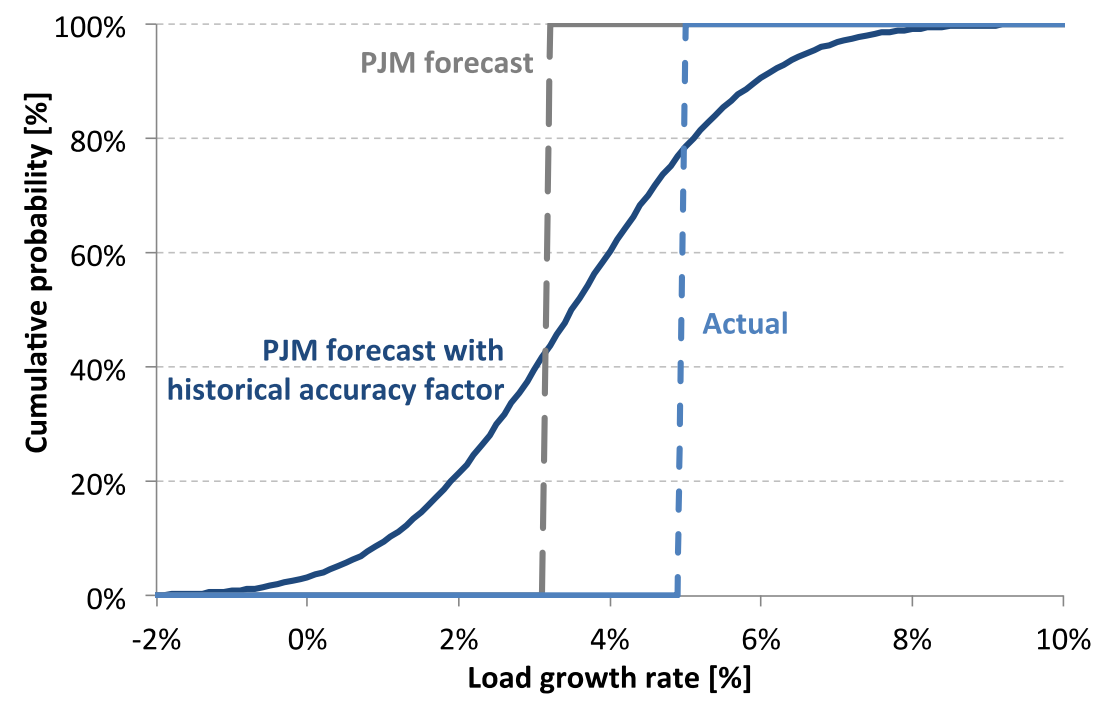

Figure 3. PJM's 2010 load growth forecast, with and without the historical accuracy factor, and actual load growth that occurred. 


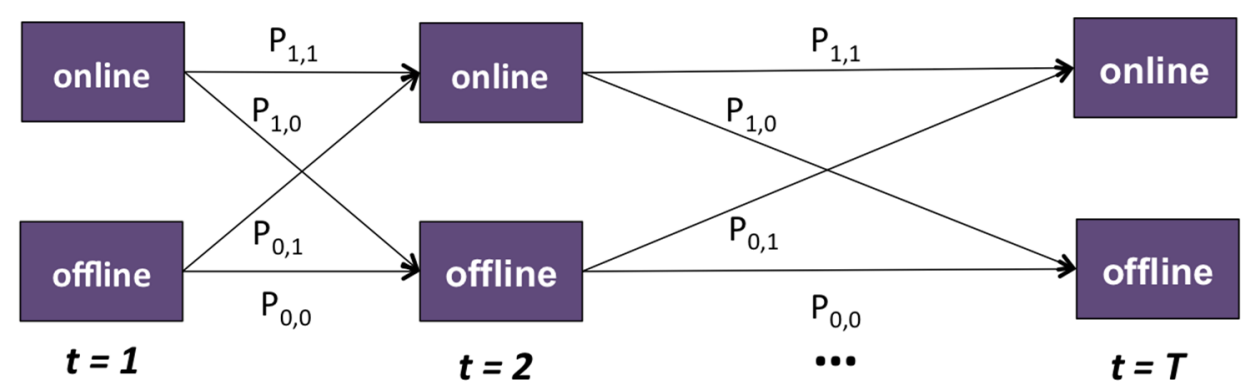

Figure 4. Forced outages 2-stage discrete Markov process

Table 4. Forced outage equations

$M O D=\frac{E F O R d^{*} 8760}{N F O}$
$P_{0,1}=\frac{1}{M O D}$
$P_{0,0}=1-P_{0,1}$
$P_{1,0}=\frac{N F O}{8760}$
$P_{1,1}=1-P_{1,0}$
$M O D=$ mean outage duration
$N F O=$ Annual number of forced outages
$E F O R d=$ Equivalent forced outage rate

Table 5. DR capacity and net import capacity, by capacity auction (PJM 2009)

\begin{tabular}{lrr}
\hline $\begin{array}{l}\text { Capacity } \\
\text { auction }\end{array}$ & $\begin{array}{r}\text { DR capacity } \\
\text { (MW) }\end{array}$ & $\begin{array}{r}\text { Net import } \\
\text { capacity (MW) }\end{array}$ \\
\hline $2009 / 2010$ & 7,290 & +320 \\
$2010 / 2011$ & 9,050 & -400 \\
\hline
\end{tabular}

Table 6. Outage equations 


Outage $_{i}=\left\{\begin{array}{l}1: \sum \text { AvailableCapacity }_{i}<\text { Load }_{i} \\ 0: \sum \text { AvailableCapacity }_{i}>\text { Load }_{i}\end{array} \quad \forall i \in I\right.$
$L O L H=\sum_{i}$ Outage $_{i} \quad \forall i \in I$
$E U E=\sum_{i}\left(\right.$ Load $_{i}-$ AvailableCapacity $\left._{i}\right) \quad \forall i \in$ Outage $_{i}=1$
$\mathrm{I}^{=}$set of 8760 annual hours $^{\text {AvailableCapacity }}$ = summed capacity of all online PJM generators, DR, net
imports, and reliable wind power at hour i
Load $_{i}=$ total PJM load at hour i
Outage $_{i}=$ binary variable indicating if an outage occurred at hour i

\section{Table 7. Comelated outage equations}

\begin{tabular}{|c|c|c|c|}
\hline fuelShortage $_{i}=$ & $\begin{array}{l}1: \operatorname{rand}() \leq P_{F S} \\
0: \operatorname{rand}()>P_{F S}\end{array} \quad \forall i \in I_{\text {winter }}$ & & $(16)$ \\
\hline$P_{1,0, i}{ }^{\prime}=\left\{\begin{array}{r}P \\
P_{1,0}-P\end{array}\right.$ & $\begin{array}{l}\text { utage,FS }: \text { fuelShortage }_{i}=1 \\
\quad * P_{F S}: \text { fuelShortage }_{i}=0\end{array}$ & $\forall i \in I_{\text {annual }}$ & $(17)$ \\
\hline$P_{1,1}{ }^{\prime}=1-P_{1,0}{ }^{\prime}$ & & & (18) \\
\hline \multicolumn{4}{|c|}{$I_{\text {annual }}=$ set of all 8760 annual hours } \\
\hline \multicolumn{4}{|c|}{$I_{\text {winter }}=$ set of 2160 winter hours } \\
\hline \multicolumn{4}{|c|}{$P_{F S}=$ Probability of a fuel shortage } \\
\hline \multicolumn{4}{|c|}{$\begin{array}{l}\text { fuelShortage }_{i}=\text { binary variable indicating if there is a fuel shortage at hour } \\
\text { i }\end{array}$} \\
\hline \multicolumn{4}{|c|}{$P_{\text {outage }, F S}=$ Probability that a generator goes offline if a fuel shortage occurs } \\
\hline
\end{tabular}




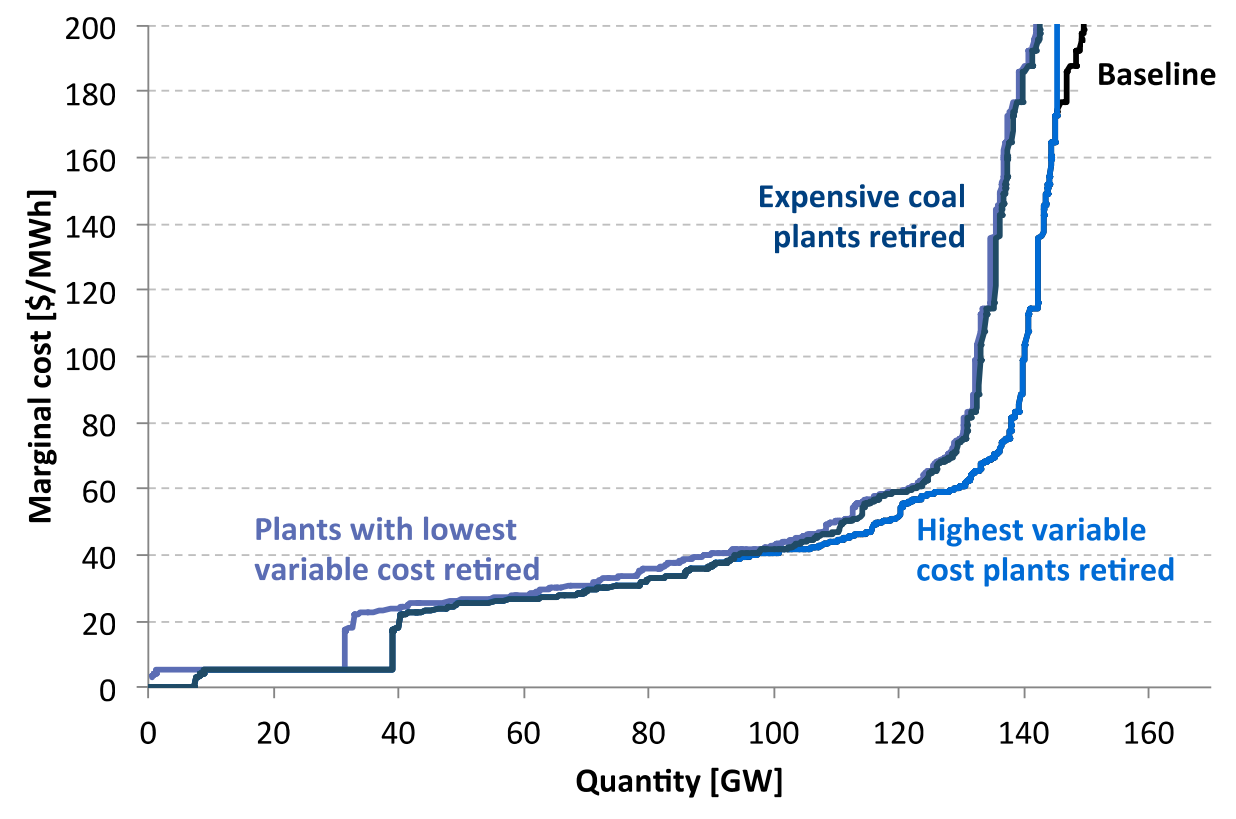

Figure 5. Energy market supply curves for baseline 20.5\% reserve margin, and $15.5 \%$ reserve margin with different types of capacity retired.

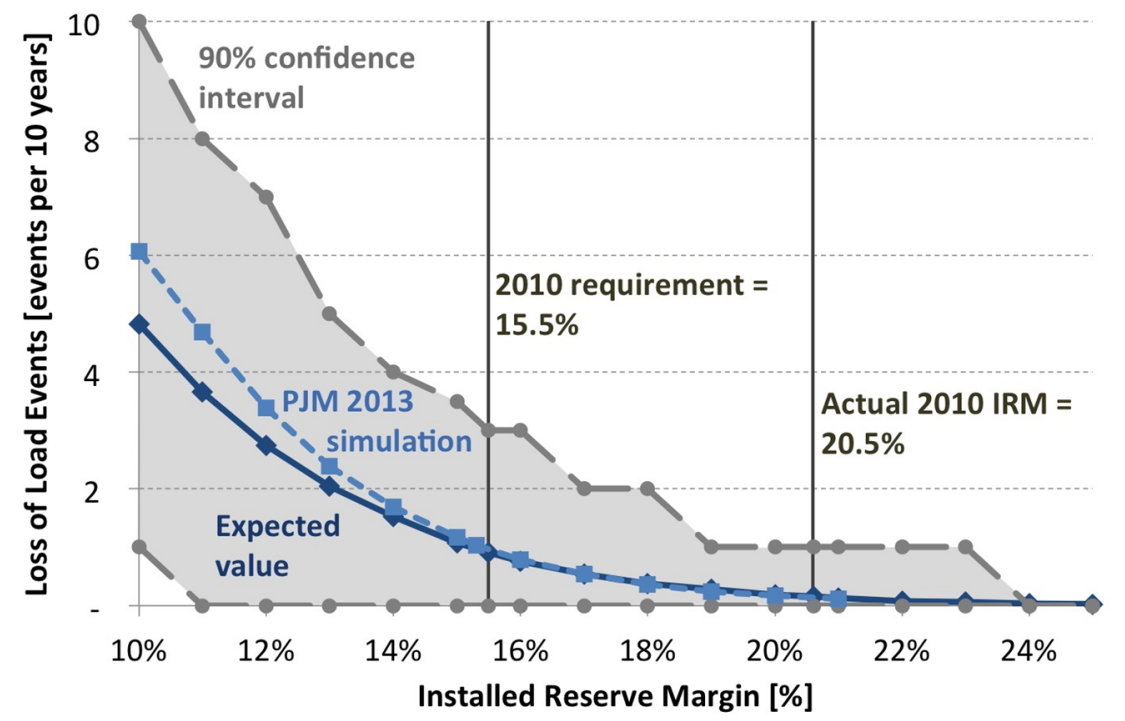

Figure 6. 2010 LOLE versus reserve margin. Also shown are results from PJM's 2013 resource adequacy modeling (recreated from (PJM 2010a)). 


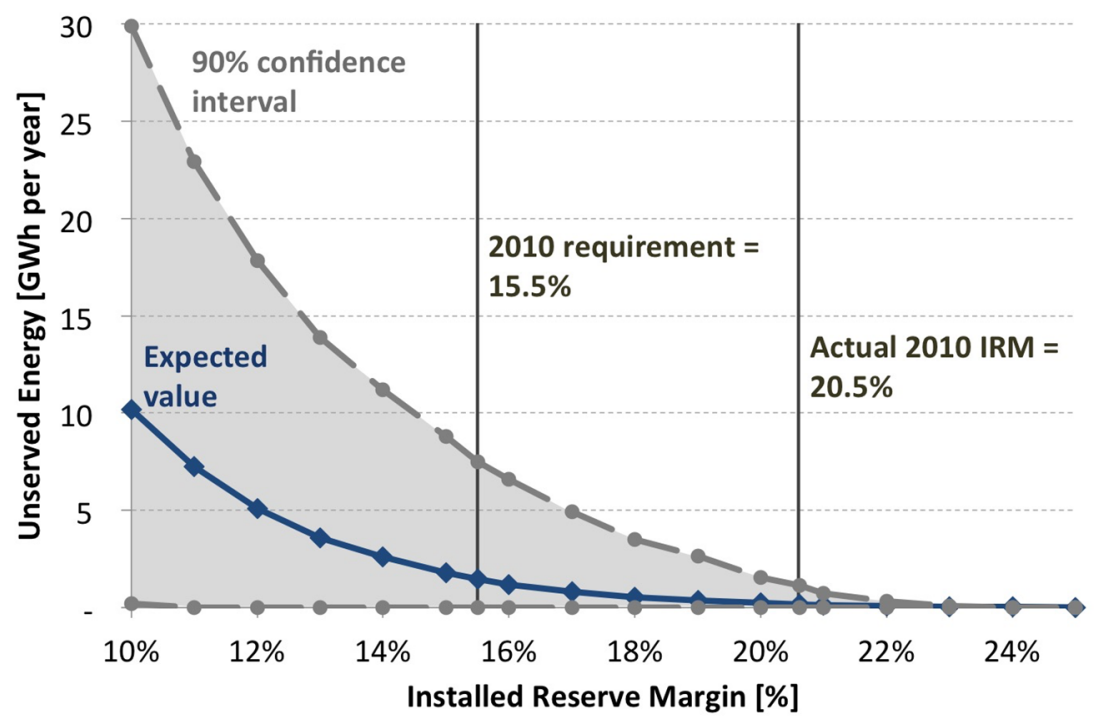

Figure 7. 2010 unserved energy versus reserve margin.

Table 8. Sensitivity of the target reserve margin and installed capacity to different reliability metrics and risk tolerances. PJM's target 2010 reserve margin was $15.5 \%(158 \mathrm{GW})$, and actual 2010 reserve margin was $20.5 \%(165 \mathrm{GW})$.

\begin{tabular}{lrrrr}
\hline & \multicolumn{3}{c}{$\begin{array}{c}\text { Optimal reserve margin [\%] } \\
\text { (installed capacity [GW]) }\end{array}$} \\
Metric & & $\begin{array}{r}\mathbf{9 0 \%} \\
\mathbf{9 5 \%}\end{array}$ & $\mathbf{9 9 \%}$ \\
\hline \multirow{2}{*}{0.1 LOLE } & Risk Neutral & Confidence & Confidence & Confidence \\
& $15.5 \%$ & $20.5 \%$ & $22 \%$ & $>25 \%$ \\
& $(158)$ & $(165)$ & $(168)$ & $(>170)$ \\
2.4 LOLH & $10 \%$ & $13 \%$ & $14 \%$ & $15 \%$ \\
& $(151)$ & $(154)$ & $(156)$ & $(158)$ \\
$0.001 \%$ UE & $10 \%$ & $13 \%$ & $14 \%$ & $16 \%$ \\
& $(151)$ & $(154)$ & $(156)$ & $(159)$ \\
\hline
\end{tabular}




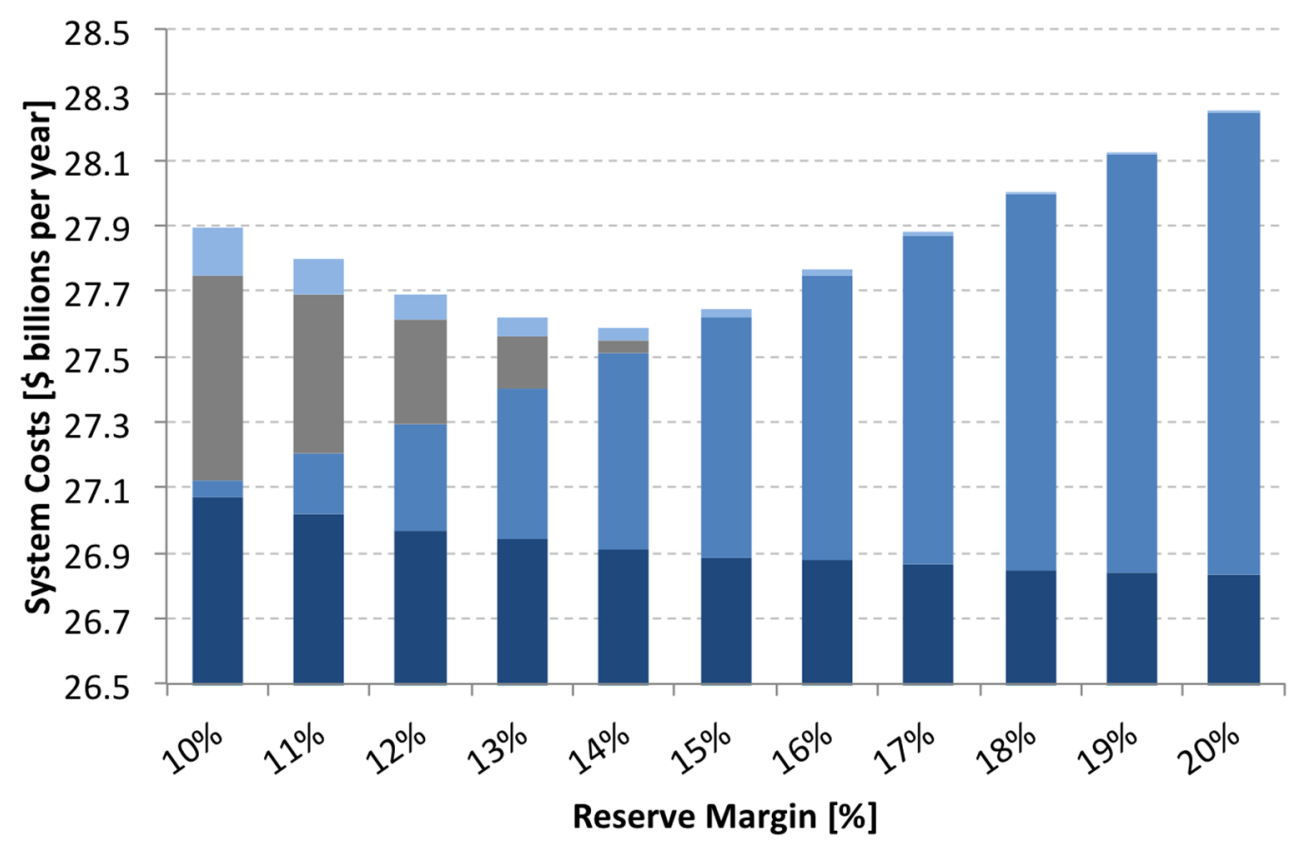

Energy market $\quad$ Capacity market $\quad$ Reserve shortages $\quad$ Outages

Figure 8. Long run system costs. Capacity market costs above a $\$ 15$ billion/ year baseline.

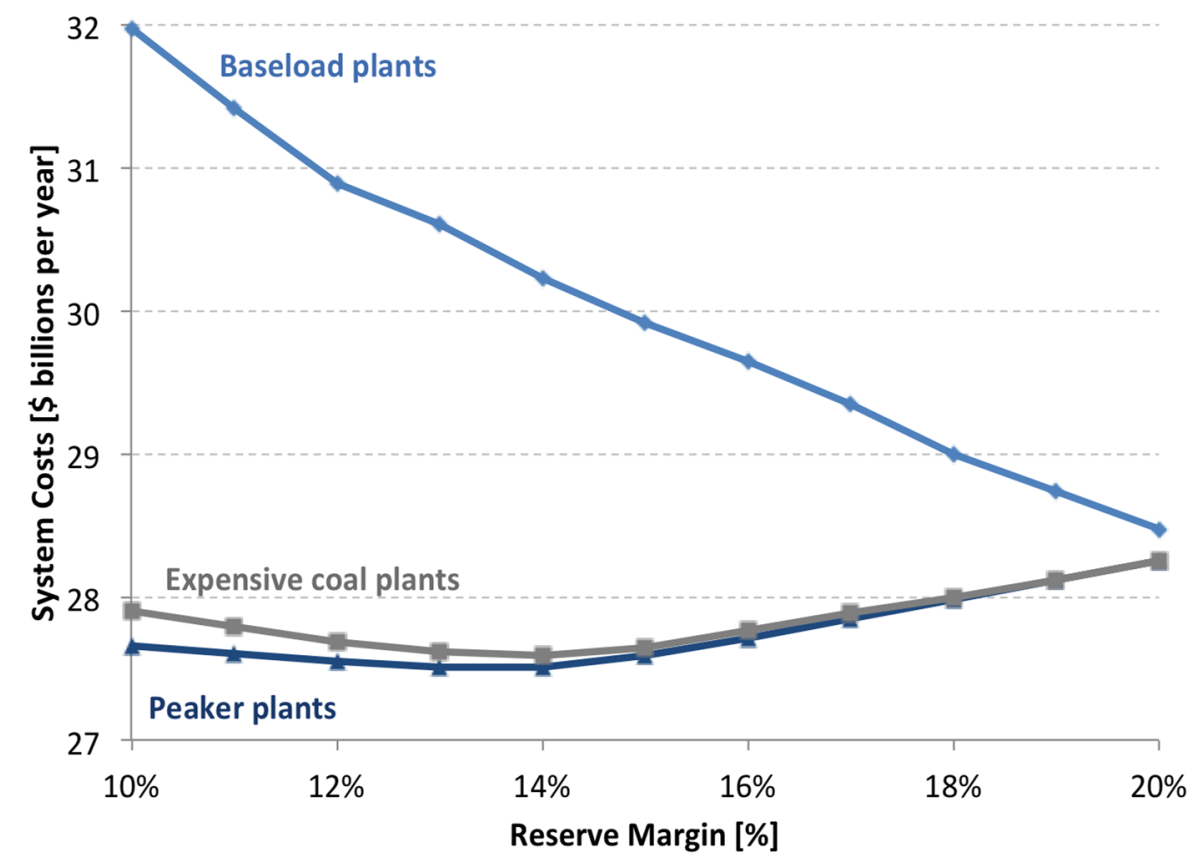

Figure 9. Long nun system costs, for different assumptions about what type of capacity is retired. 


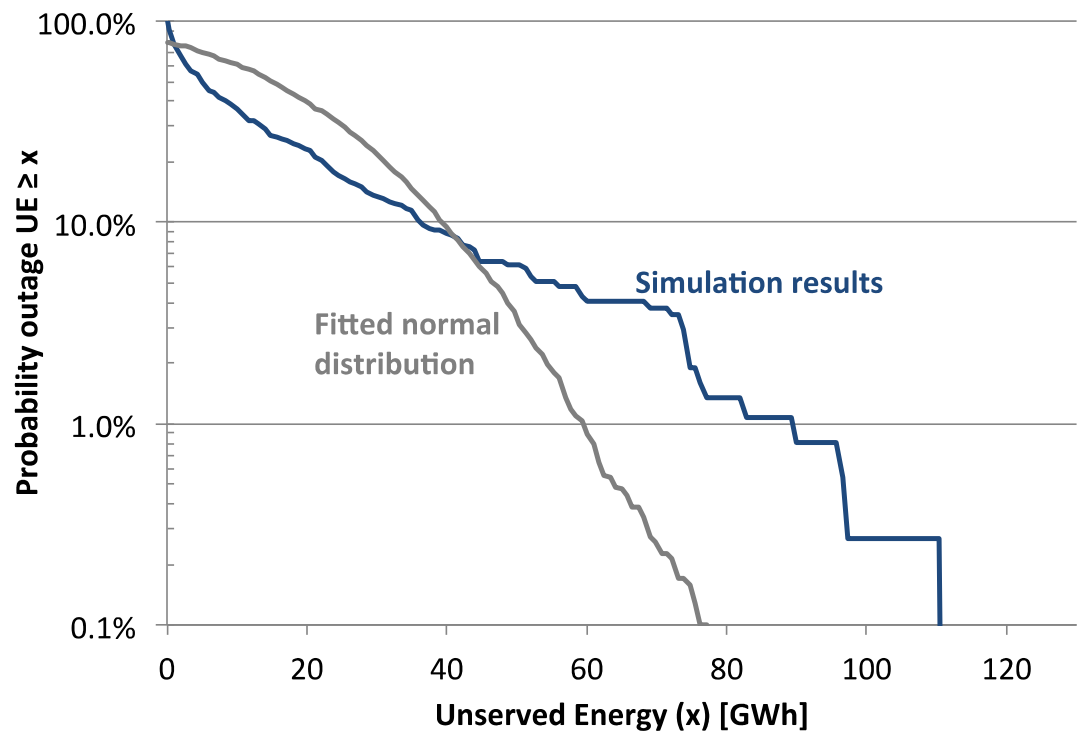

Figure 10. Distribution of the size of simulated outages, in terms of unserved energy, versus a fitted nomal distribution. Assumed reserve margin is $15.5 \%$.

Table 9. Outage summary statistics, $15.5 \%$ reserve margin

\begin{tabular}{lrrr}
\hline & $\begin{array}{r}\text { Expected } \\
\text { value }\end{array}$ & $\begin{array}{r}\mathbf{9 0 \%} \text { Confidence } \\
\text { Interval }\end{array}$ & Maximum \\
\hline Outage duration [hours] & 4 & $1-9$ & 10 \\
Largest magnitude [GW] & 3 & $0-10$ & 17 \\
Total load shed [GWh] & 13 & $0-54$ & 110 \\
\hline
\end{tabular}




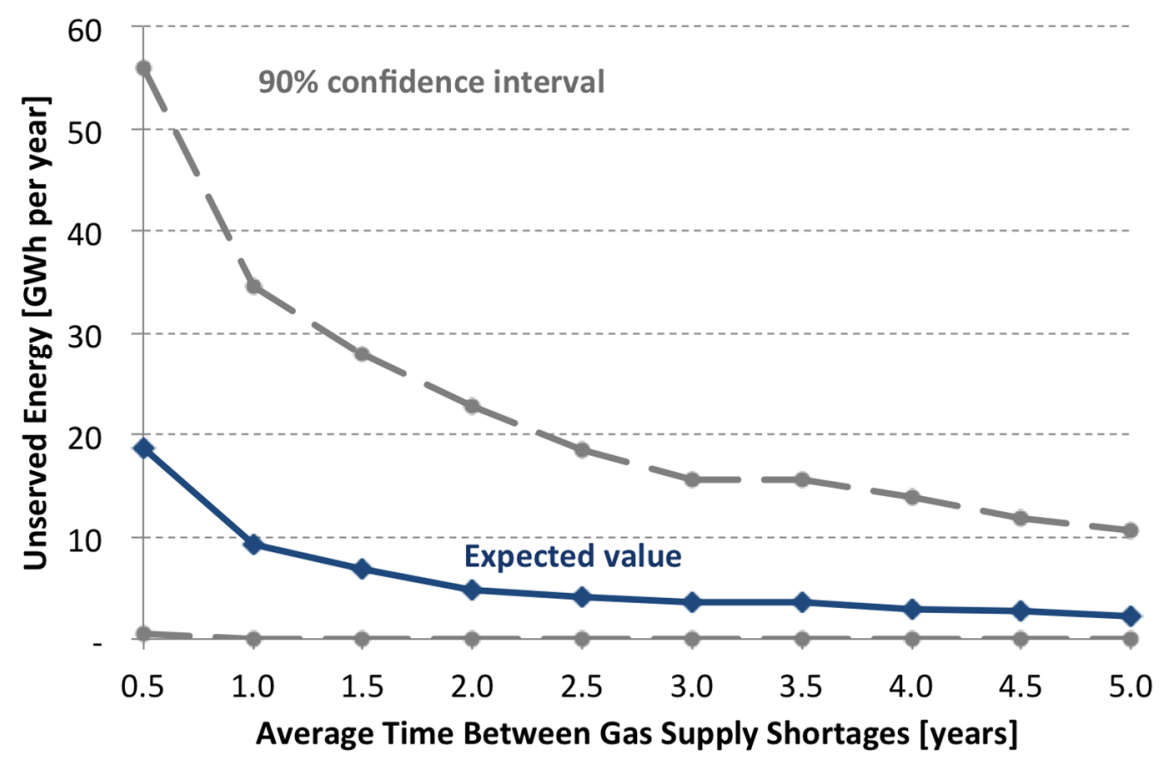

Figure 11. Sensitivity of unserved energy to natural gas supply shortages that can occur at any point during the year, and force all PJM gas generators offline. Evaluated at $15.5 \%$ IRM.

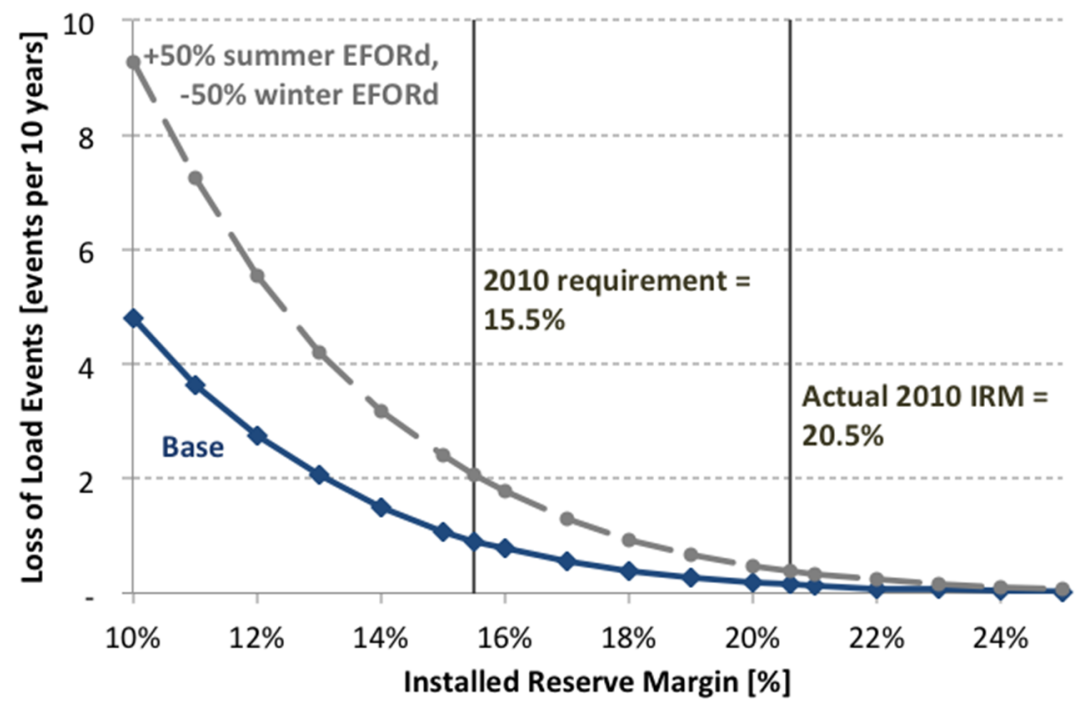

Figure 12. Sensitivity of LOLE expected value to forced outage rate (EFORd). 


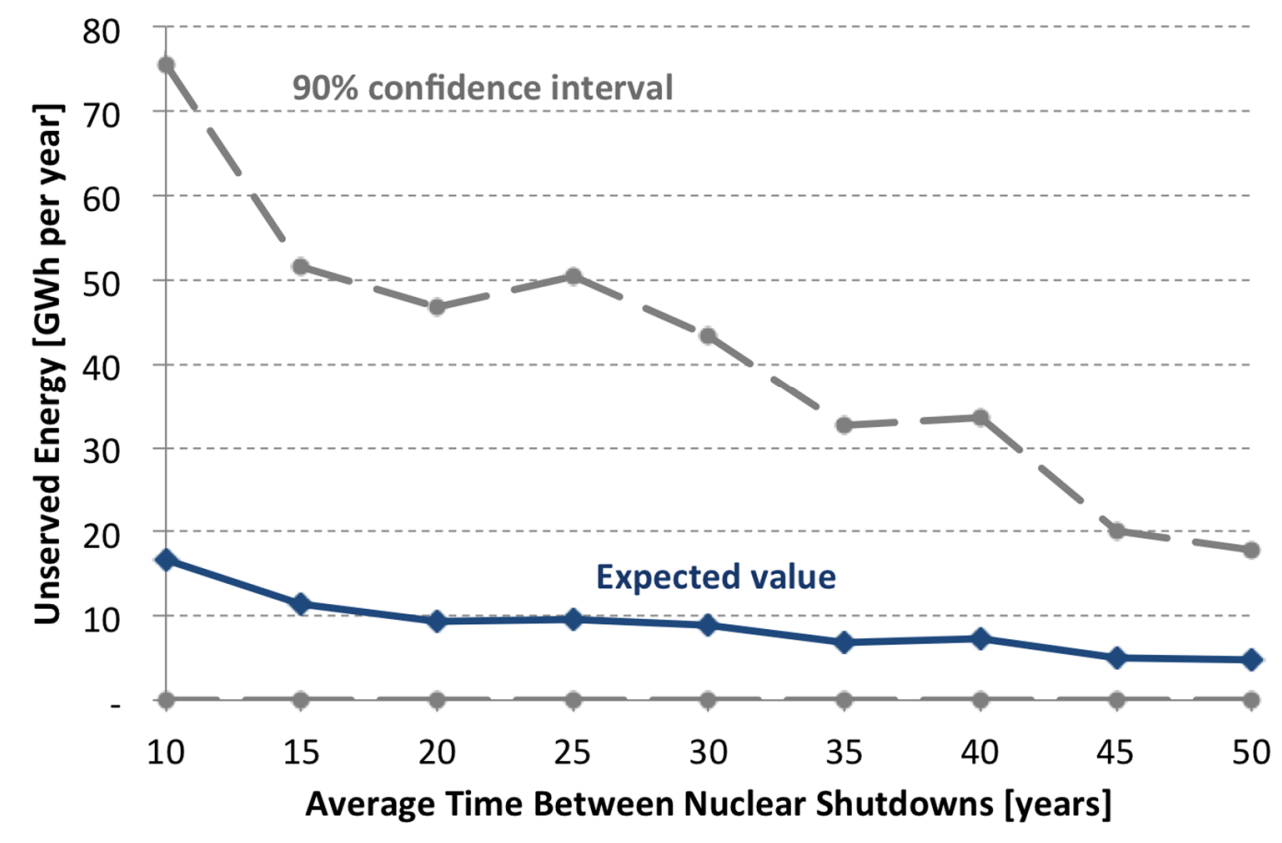

Figure 13. Sensitivity of unserved energy to regulatory actions that force all PJM nuclear generators offline simultaneously for six months. Evaluated at $15.5 \%$ IRM.

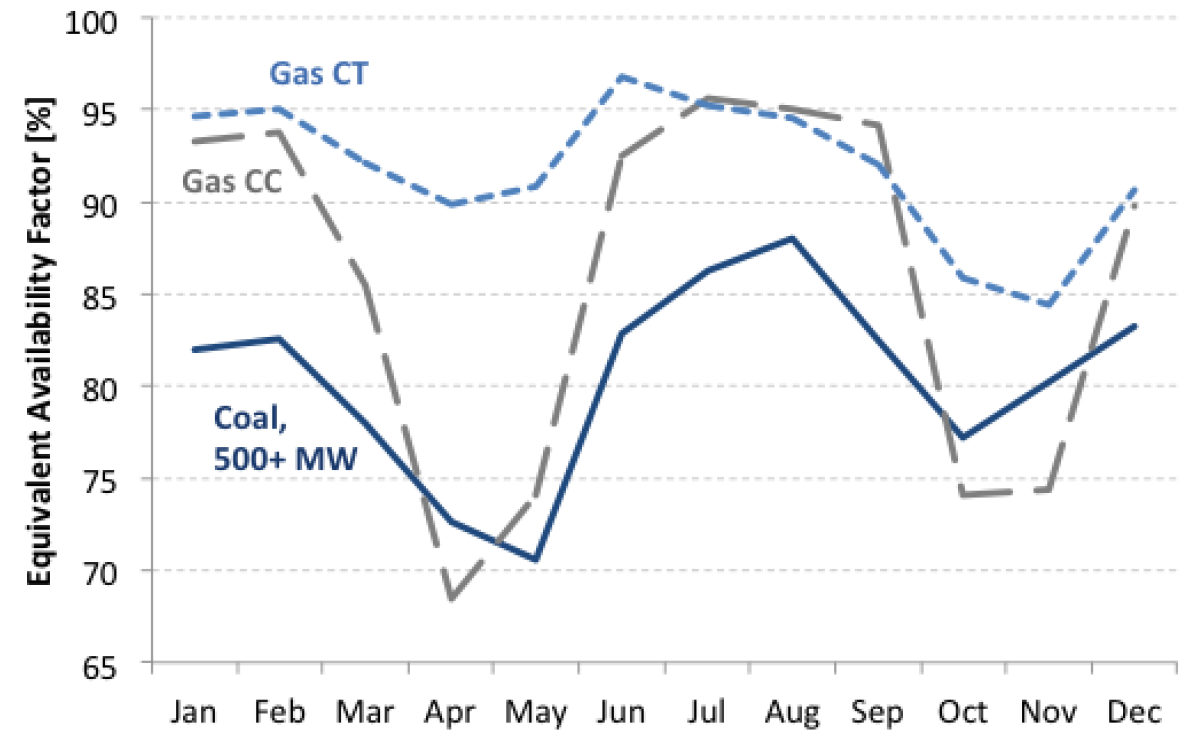

Figure A.1. Equivalent availability factor, PJM generators, 2010 (Bresler, 2012).

Table A.1. Accuracy statistics of the load forecast model, both training error (2000 - 2009) and test prediction emor (2010). 


\begin{tabular}{lrrrr}
\hline & \multicolumn{2}{c}{ Training, 1990 - 2009 } & \multicolumn{2}{c}{ Test, 2010 } \\
& $\begin{array}{r}\text { RMSE } \\
\text { [MW] }\end{array}$ & $\begin{array}{r}\text { NRMSE } \\
\text { PJM Region }\end{array}$ & $\begin{array}{r}\text { RMSE } \\
\text { [MW] }\end{array}$ & $\begin{array}{r}\text { NRMSE } \\
\text { [\%] }\end{array}$ \\
\hline PJM Classic & 1690 & 4.0 & 1800 & 4.5 \\
AEP & 790 & 5.2 & 910 & 6.7 \\
Allegheny Energy & 300 & 5.3 & 330 & 6.2 \\
Dayton Power \& Light & 130 & 4.7 & 140 & 6.1 \\
Dominion Virginia & 640 & 3.3 & 760 & 5.8 \\
Duquesne Light Co & 80 & 4.1 & 90 & 5.2 \\
Exelon - Commonwealth Edison & 930 & 5.6 & 1000 & 6.9 \\
Rockland Energy & 20 & 4.2 & 20 & 5.1 \\
PJM total & 3510 & 3.5 & 3840 & 4.3 \\
\hline
\end{tabular}

\section{Table A.2. Detailed regression results for the PJM Classic region.}

Note: Dependent variable is residuals from the long-term trend regression (see main paper, step 1).

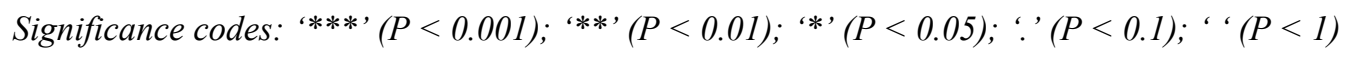

\begin{tabular}{|c|c|c|c|c|c|}
\hline Variable & Estimate & Std. Error & $t$ value & Significance & Notes \\
\hline (Intercept) & 1.77E-01 & 2.81E-02 & 6.286 & $* * *$ & \\
\hline isTue & $1.07 \mathrm{E}-02$ & $6.80 \mathrm{E}-04$ & 15.694 & $* * *$ & \\
\hline isWed & 1.39E-02 & $6.81 \mathrm{E}-04$ & 20.444 & *** & \\
\hline isThu & 1.46E-02 & 6.84E-04 & 21.289 & *** & \\
\hline isFri & $1.66 \mathrm{E}-03$ & $6.89 \mathrm{E}-04$ & 2.409 & * & \\
\hline isSat & $-8.54 \mathrm{E}-02$ & $6.83 \mathrm{E}-04$ & -125.053 & $* * *$ & \\
\hline isSun & $-1.15 \mathrm{E}-01$ & $6.84 \mathrm{E}-04$ & -168.839 & $* * *$ & \\
\hline isMLK & $-1.08 E-02$ & 3.51E-03 & -3.066 & ** & \\
\hline isPresidentsDay & 3.33E-03 & $3.54 \mathrm{E}-03$ & 0.942 & & \\
\hline isGoodFriday & $-5.21 E-02$ & 3.49E-03 & -14.962 & $* * *$ & \\
\hline isMemorialDay & $-1.01 \mathrm{E}-01$ & $4.26 \mathrm{E}-03$ & -23.752 & *** & \\
\hline isMemorialDayWeekend & $-2.88 \mathrm{E}-02$ & 2.71E-03 & -10.602 & *** & \\
\hline isJuly4 & $-1.14 \mathrm{E}-01$ & $3.56 \mathrm{E}-03$ & -31.962 & *** & \\
\hline isLaborDay & $-1.13 E-01$ & $4.24 \mathrm{E}-03$ & -26.601 & $* * *$ & \\
\hline isLaborDayWeekend & $-2.28 \mathrm{E}-02$ & 2.61E-03 & -8.707 & $* * *$ & \\
\hline isChristmas & $-1.42 \mathrm{E}-01$ & 4.63E-03 & -30.571 & *** & \\
\hline isXmasEveEve & $-2.11 \mathrm{E}-03$ & $4.63 \mathrm{E}-03$ & -0.456 & & \\
\hline isChristmasEve & $-7.60 \mathrm{E}-02$ & 4.63E-03 & -16.405 & $* * *$ & \\
\hline isXMasWk & $-2.53 \mathrm{E}-02$ & 3.49E-03 & -7.249 & $* * *$ & \\
\hline
\end{tabular}




\begin{tabular}{|c|c|c|c|c|}
\hline Variable & Estimate & Std. Error & t value & Significance \\
\hline XMasLights & 1.35E-02 & 2.64E-03 & 5.116 & ${ }^{* * *} \operatorname{Dec} 4-\operatorname{Dec} 22$ \\
\hline isThanksgiving & $-1.50 \mathrm{E}-01$ & $3.78 \mathrm{E}-03$ & -39.591 & $* * *$ \\
\hline isThanksgivingFriday & $-1.01 \mathrm{E}-01$ & $3.78 \mathrm{E}-03$ & -26.69 & ${ }^{* * *}$ Day after Thanksgiving \\
\hline isNewYearsDay & $-9.73 E-02$ & $3.60 \mathrm{E}-03$ & -27.021 & $* \star *$ \\
\hline isNewYearsEve & $-5.09 E-02$ & 4.53E-03 & -11.234 & $* * *$ \\
\hline isThanksgivingWeek & $-4.43 E-03$ & $1.94 \mathrm{E}-03$ & -2.28 & ${ }^{*}$ Mon - Sun, Thanksgiving week \\
\hline isXmasDayAfter & $-4.67 E-02$ & $3.82 \mathrm{E}-03$ & -12.226 & ${ }^{* * *} \operatorname{Dec} 26$ \\
\hline isFeb & 5.69E-01 & 3.56E-02 & 15.97 & $* \star *$ \\
\hline is $\mathrm{H} 1$ & $-1.27 \mathrm{E}-01$ & $3.16 \mathrm{E}-03$ & -40.275 & $* * *$ \\
\hline is $\mathrm{H} 2$ & $-1.58 \mathrm{E}-01$ & 3.16E-03 & -49.848 & $* * *$ \\
\hline isH3 & -1.71E-01 & 3.16E-03 & -54.034 & $* * *$ \\
\hline is $\mathrm{H} 4$ & $-1.72 \mathrm{E}-01$ & $3.16 \mathrm{E}-03$ & -54.256 & $* * *$ \\
\hline isH5 & $-1.52 \mathrm{E}-01$ & 3.16E-03 & -48.069 & $* * *$ \\
\hline isH6 & $-9.39 E-02$ & $3.16 \mathrm{E}-03$ & -29.672 & $* \star *$ \\
\hline is $\mathrm{H} 7$ & $-2.94 \mathrm{E}-05$ & 3.16E-03 & -0.009 & \\
\hline is $\mathrm{H} 8$ & 5.38E-02 & $3.16 \mathrm{E}-03$ & 16.991 & $* * *$ \\
\hline isH9 & 6.71E-02 & $3.16 \mathrm{E}-03$ & 21.204 & $* * *$ \\
\hline is $\mathrm{H} 10$ & 7.29E-02 & 3.16E-03 & 23.044 & $* * *$ \\
\hline isH11 & 7.32E-02 & 3.16E-03 & 23.147 & $* * *$ \\
\hline isH12 & 6.47E-02 & 3.16E-03 & 20.432 & $* * *$ \\
\hline isH13 & 5.10E-02 & 3.16E-03 & 16.111 & $* * *$ \\
\hline isH14 & 3.91E-02 & $3.16 \mathrm{E}-03$ & 12.351 & $* * *$ \\
\hline isH15 & 2.65E-02 & $3.16 \mathrm{E}-03$ & 8.384 & $* * *$ \\
\hline isH16 & 2.57E-02 & 3.16E-03 & 8.106 & $* * *$ \\
\hline isH17 & 5.68E-02 & 3.16E-03 & 17.949 & $* * *$ \\
\hline isH18 & 1.31E-01 & $3.16 \mathrm{E}-03$ & 41.321 & $* * *$ \\
\hline isH19 & $1.45 \mathrm{E}-01$ & $3.16 \mathrm{E}-03$ & 45.811 & $* * *$ \\
\hline isH2O & 1.32E-01 & 3.16E-03 & 41.601 & $* * *$ \\
\hline isH21 & 1.10E-01 & $3.16 \mathrm{E}-03$ & 34.847 & $* * *$ \\
\hline isH22 & 6.87E-02 & $3.16 \mathrm{E}-03$ & 21.71 & $* * *$ \\
\hline isH23 & 3.11E-03 & 3.16E-03 & 0.984 & \\
\hline isH24 & $-6.97 \mathrm{E}-02$ & 3.16E-03 & -22.036 & $* * *$ \\
\hline isMar & 7.47E-01 & $3.43 E-02$ & 21.815 & $* * *$ \\
\hline isApr & $6.20 \mathrm{E}-01$ & 3.64E-02 & 17.054 & $* * *$ \\
\hline isMay & 1.26E-02 & 4.36E-02 & 0.289 & \\
\hline isJun & $-2.54 \mathrm{E}+00$ & 1.17E-01 & -21.658 & $* * *$ \\
\hline isJul & $1.15 \mathrm{E}+00$ & $6.10 \mathrm{E}-02$ & 18.865 & $* * *$ \\
\hline isAug & 7.86E-03 & 3.85E-02 & 0.204 & \\
\hline isSep & 1.17E-02 & 3.62E-02 & 0.323 & \\
\hline isOct & $3.58 \mathrm{E}-01$ & 3.40E-02 & 10.54 & $* * *$ \\
\hline isNov & $5.44 \mathrm{E}-01$ & 3.85E-02 & 14.11 & $* * *$ \\
\hline
\end{tabular}




\begin{tabular}{|c|c|c|c|c|c|}
\hline Variable & Estimate & Std. Error & t value & Significance & Notes \\
\hline isDec & $1.59 \mathrm{E}+00$ & $1.07 \mathrm{E}-01$ & 14.806 & *** & * \\
\hline sun.hours & $6.31 \mathrm{E}-04$ & 4.97E-05 & 12.698 & & * Daily daylight length, DC [mins] \\
\hline isFeb:isH1 & 2.94E-02 & $4.52 \mathrm{E}-03$ & 6.496 & *** & $*$ \\
\hline isFeb:isH2 & 3.16E-02 & 4.52E-03 & 6.99 & *** & * \\
\hline isFeb:isH3 & 3.39E-02 & $4.52 \mathrm{E}-03$ & 7.51 & *** & $*$ \\
\hline isFeb:isH4 & 3.57E-02 & $4.52 \mathrm{E}-03$ & 7.909 & $* * *$ & $*$ \\
\hline isFeb:isH5 & 3.75E-02 & 4.52E-03 & 8.29 & *** & * \\
\hline isFeb:isH6 & 4.05E-02 & $4.52 \mathrm{E}-03$ & 8.973 & *** & $*$ \\
\hline isFeb:isH7 & 4.15E-02 & $4.52 \mathrm{E}-03$ & 9.174 & $* * *$ & $*$ \\
\hline isFeb:isH8 & 3.38E-02 & 4.52E-03 & 7.483 & $* * *$ & $*$ \\
\hline isFeb:isH9 & 3.47E-02 & $4.52 \mathrm{E}-03$ & 7.673 & $* * *$ & $*$ \\
\hline isFeb:isH10 & $3.12 \mathrm{E}-02$ & $4.52 \mathrm{E}-03$ & 6.913 & $* * *$ & $*$ \\
\hline isFeb:isH11 & 2.77E-02 & $4.52 \mathrm{E}-03$ & 6.127 & $* * *$ & $*$ \\
\hline isFeb:isH12 & 2.41E-02 & $4.52 \mathrm{E}-03$ & 5.341 & $* * *$ & $*$ \\
\hline isFeb:isH13 & $2.12 \mathrm{E}-02$ & $4.52 \mathrm{E}-03$ & 4.689 & $* * *$ & $*$ \\
\hline isFeb:isH14 & $1.89 \mathrm{E}-02$ & $4.52 \mathrm{E}-03$ & 4.192 & $* * *$ & $*$ \\
\hline isFeb:isH15 & 1.67E-02 & $4.52 \mathrm{E}-03$ & 3.688 & $* * *$ & $*$ \\
\hline isFeb:isH16 & $1.22 \mathrm{E}-02$ & 4.52E-03 & 2.701 & ** & $*$ \\
\hline isFeb:isH17 & $-1.83 E-03$ & 4.52E-03 & -0.404 & & \\
\hline isFeb:isH18 & $-2.08 E-02$ & $4.52 \mathrm{E}-03$ & -4.611 & $* * *$ & $*$ \\
\hline isFeb:isH19 & $1.29 \mathrm{E}-02$ & $4.52 \mathrm{E}-03$ & 2.855 & ** & $*$ \\
\hline isFeb:isH20 & $1.84 \mathrm{E}-02$ & $4.52 \mathrm{E}-03$ & 4.063 & $* * *$ & $*$ \\
\hline isFeb:isH21 & $2.00 \mathrm{E}-02$ & $4.52 \mathrm{E}-03$ & 4.416 & *** & $*$ \\
\hline isFeb:isH22 & 2.13E-02 & $4.52 \mathrm{E}-03$ & 4.708 & $* * *$ & $*$ \\
\hline isFeb:isH23 & 2.30E-02 & 4.52E-03 & 5.092 & $* * *$ & $*$ \\
\hline isFeb:isH24 & $2.52 \mathrm{E}-02$ & $4.52 \mathrm{E}-03$ & 5.587 & *** & $*$ \\
\hline isH1:isMar & 2.87E-02 & $4.40 \mathrm{E}-03$ & 6.519 & $* * *$ & * \\
\hline isH2:isMar & 2.72E-02 & 4.40E-03 & 6.178 & $* * *$ & $*$ \\
\hline isH3:isMar & 2.67E-02 & 4.41E-03 & 6.059 & $* * *$ & $*$ \\
\hline isH4:isMar & 2.72E-02 & 4.40E-03 & 6.195 & *** & * \\
\hline isH5:isMar & 2.92E-02 & 4.40E-03 & 6.644 & $* * *$ & $*$ \\
\hline isH6:isMar & 3.71E-02 & 4.40E-03 & 8.44 & $* * *$ & $*$ \\
\hline isH7:isMar & 3.88E-02 & 4.40E-03 & 8.829 & *** & * \\
\hline isH8:isMar & 4.11E-02 & 4.40E-03 & 9.36 & $* * *$ & $*$ \\
\hline isH9:isMar & 4.70E-02 & 4.40E-03 & 10.692 & $* * *$ & * \\
\hline isH10:isMar & 4.78E-02 & 4.40E-03 & 10.868 & *** & $*$ \\
\hline isH11:isMar & 4.79E-02 & 4.40E-03 & 10.889 & $* * *$ & $*$ \\
\hline isH12:isMar & 4.72E-02 & 4.40E-03 & 10.747 & $* * *$ & $*$ \\
\hline isH13:isMar & 4.69E-02 & 4.40E-03 & 10.665 & $* * *$ & $*$ \\
\hline isH14:isMar & 4.65E-02 & 4.40E-03 & 10.569 & $* * *$ & $*$ \\
\hline isH15:isMar & 4.39E-02 & 4.40E-03 & 9.977 & $* * *$ & $*$ \\
\hline
\end{tabular}




\begin{tabular}{|c|c|c|c|c|c|}
\hline Variable & Estimate & Std. Error & t value & Significance & Notes \\
\hline isH16:isMar & 3.62E-02 & 4.40E-03 & 8.224 & $* * *$ & \\
\hline isH17:isMar & 1.16E-02 & 4.40E-03 & 2.641 & $* *$ & \\
\hline isH18:isMar & $-3.90 \mathrm{E}-02$ & 4.40E-03 & -8.862 & $* * *$ & \\
\hline isH19:isMar & $-4.21 \mathrm{E}-03$ & 4.40E-03 & -0.957 & & \\
\hline isH20:isMar & 2.87E-02 & 4.40E-03 & 6.519 & $* * *$ & \\
\hline isH21:isMar & 3.69E-02 & 4.40E-03 & 8.388 & $* * *$ & \\
\hline isH22:isMar & $3.58 \mathrm{E}-02$ & 4.40E-03 & 8.134 & $* \star \star$ & \\
\hline isH23:isMar & $3.14 \mathrm{E}-02$ & 4.40E-03 & 7.15 & $* * *$ & \\
\hline isH24:isMar & 2.68E-02 & 4.40E-03 & 6.097 & $* * *$ & \\
\hline isH1:isApr & $1.18 \mathrm{E}-02$ & 4.46E-03 & 2.636 & $* *$ & \\
\hline isH2:isApr & $-7.41 E-04$ & 4.46E-03 & -0.166 & & \\
\hline isH3:isApr & $-1.02 E-02$ & 4.49E-03 & -2.278 & * & \\
\hline isH4:isApr & $-1.43 E-02$ & 4.46E-03 & -3.198 & $\star \star$ & \\
\hline isH5:isApr & $-1.66 \mathrm{E}-02$ & 4.46E-03 & -3.731 & $* * *$ & \\
\hline isH6:isApr & $-9.39 E-03$ & 4.46E-03 & -2.106 & * & \\
\hline isH7:isApr & $-4.58 \mathrm{E}-03$ & 4.46E-03 & -1.026 & & \\
\hline isH8:isApr & $9.25 \mathrm{E}-03$ & 4.46E-03 & 2.074 & * & \\
\hline isH9:isApr & 3.23E-02 & 4.46E-03 & 7.236 & $* * *$ & \\
\hline isH10:isApr & 4.74E-02 & 4.46E-03 & 10.628 & $* * *$ & \\
\hline isH11:isApr & 6.00E-02 & 4.46E-03 & 13.452 & $* * *$ & \\
\hline isH12:isApr & 6.94E-02 & 4.46E-03 & 15.564 & $* * *$ & \\
\hline isH13:isApr & 7.70E-02 & 4.46E-03 & 17.276 & $* * *$ & \\
\hline isH14:isApr & 8.30E-02 & 4.46E-03 & 18.612 & $* * *$ & \\
\hline isH15:isApr & 8.46E-02 & 4.46E-03 & 18.97 & $* \star \star$ & \\
\hline isH16:isApr & 7.71E-02 & 4.46E-03 & 17.298 & $* * *$ & \\
\hline isH17:isApr & 4.44E-02 & 4.46E-03 & 9.96 & $* * *$ & \\
\hline isH18:isApr & $-2.94 \mathrm{E}-02$ & 4.46E-03 & -6.601 & $* \star \star$ & \\
\hline isH19:isApr & $-4.53 E-02$ & 4.46E-03 & -10.158 & $* * *$ & \\
\hline isH20:isApr & $-1.10 \mathrm{E}-02$ & 4.46E-03 & -2.472 & * & \\
\hline isH21:isApr & 4.67E-02 & 4.46E-03 & 10.472 & $* * *$ & \\
\hline isH22:isApr & 5.29E-02 & 4.46E-03 & 11.867 & $* * *$ & \\
\hline isH23:isApr & 4.13E-02 & 4.46E-03 & 9.253 & $* * *$ & \\
\hline isH24:isApr & $2.48 \mathrm{E}-02$ & 4.46E-03 & 5.572 & $\star * \star$ & \\
\hline isH1:isMay & $-2.65 E-02$ & 4.54E-03 & -5.847 & $* * *$ & \\
\hline isH2:isMay & $-4.77 \mathrm{E}-02$ & 4.54E-03 & -10.511 & $\star \star \star *$ & \\
\hline isH3:isMay & $-6.38 \mathrm{E}-02$ & 4.54E-03 & -14.05 & $* \star \star$ & \\
\hline isH4:isMay & -7.67E-02 & 4.54E-03 & -16.904 & $* * *$ & \\
\hline isH5:isMay & $-8.53 E-02$ & 4.54E-03 & -18.801 & $* \star *$ & \\
\hline isH6:isMay & $-8.81 E-02$ & 4.54E-03 & -19.426 & $* * *$ & \\
\hline isH7:isMay & $-9.21 \mathrm{E}-02$ & 4.54E-03 & -20.297 & $* * *$ & \\
\hline isH8:isMay & $-6.09 E-02$ & 4.54E-03 & -13.425 & $* * *$ & \\
\hline
\end{tabular}




\begin{tabular}{|c|c|c|c|c|c|}
\hline Variable & Estimate & Std. Error & $\mathrm{t}$ value & Significance & Notes \\
\hline isH9:isMay & $-2.11 \mathrm{E}-02$ & 4.54E-03 & -4.655 & $* * *$ & \\
\hline isH10:isMay & $1.01 \mathrm{E}-02$ & 4.54E-03 & 2.224 & * & \\
\hline isH11:isMay & 3.70E-02 & 4.54E-03 & 8.158 & $* * *$ & \\
\hline isH12:isMay & 5.92E-02 & $4.54 \mathrm{E}-03$ & 13.044 & $* * *$ & \\
\hline isH13:isMay & 7.75E-02 & $4.54 \mathrm{E}-03$ & 17.077 & $* * *$ & \\
\hline isH14:isMay & 9.31E-02 & 4.54E-03 & 20.525 & $* * *$ & \\
\hline isH15:isMay & $1.04 \mathrm{E}-01$ & $4.54 \mathrm{E}-03$ & 22.816 & $* * *$ & \\
\hline isH16:isMay & 1.03E-01 & 4.54E-03 & 22.721 & $* * *$ & \\
\hline isH17:isMay & 7.34E-02 & 4.54E-03 & 16.182 & $* * *$ & \\
\hline isH18:isMay & $-4.80 \mathrm{E}-03$ & $4.54 \mathrm{E}-03$ & -1.058 & & \\
\hline isH19:isMay & $-3.53 E-02$ & $4.54 \mathrm{E}-03$ & -7.788 & $* * *$ & \\
\hline isH20:isMay & $-3.07 E-02$ & 4.54E-03 & -6.76 & $* * *$ & \\
\hline isH21:isMay & 1.94E-02 & $4.54 \mathrm{E}-03$ & 4.281 & $* * *$ & \\
\hline isH22:isMay & 4.21E-02 & $4.54 \mathrm{E}-03$ & 9.276 & $* * *$ & \\
\hline isH23:isMay & 2.59E-02 & 4.54E-03 & 5.702 & $* * *$ & \\
\hline isH24:isMay & 1.33E-03 & 4.54E-03 & 0.293 & & \\
\hline isH1:isJun & $-1.35 \mathrm{E}-01$ & $6.43 \mathrm{E}-03$ & -20.974 & $* * *$ & \\
\hline isH2:isJun & $-1.65 E-01$ & $6.43 \mathrm{E}-03$ & -25.615 & $* * *$ & \\
\hline isH3:isJun & $-1.90 \mathrm{E}-01$ & $6.43 \mathrm{E}-03$ & -29.586 & $* * *$ & \\
\hline isH4:isJun & $-2.12 \mathrm{E}-01$ & $6.43 \mathrm{E}-03$ & -32.975 & $* * *$ & \\
\hline isH5:isJun & $-2.30 \mathrm{E}-01$ & $6.43 \mathrm{E}-03$ & -35.685 & $* * *$ & \\
\hline isH6:isJun & $-2.51 \mathrm{E}-01$ & $6.43 \mathrm{E}-03$ & -38.996 & $* * *$ & \\
\hline isH7:isJun & $-2.69 \mathrm{E}-01$ & $6.43 \mathrm{E}-03$ & -41.868 & $* * *$ & \\
\hline isH8:isJun & $-2.30 \mathrm{E}-01$ & $6.43 \mathrm{E}-03$ & -35.732 & $* * *$ & \\
\hline isH9:isJun & $-1.70 \mathrm{E}-01$ & $6.43 E-03$ & -26.446 & $* * *$ & \\
\hline isH10:isJun & $-1.20 \mathrm{E}-01$ & $6.43 \mathrm{E}-03$ & -18.598 & $* * *$ & \\
\hline isH11:isJun & $-7.49 \mathrm{E}-02$ & $6.43 E-03$ & -11.645 & $* * *$ & \\
\hline isH12:isJun & $-3.60 \mathrm{E}-02$ & $6.43 E-03$ & -5.599 & $* * *$ & \\
\hline isH13:isJun & $-3.36 \mathrm{E}-03$ & $6.43 \mathrm{E}-03$ & -0.523 & & \\
\hline isH14:isJun & $2.41 \mathrm{E}-02$ & $6.43 E-03$ & 3.754 & $* * *$ & \\
\hline isH15:isJun & 4.57E-02 & $6.43 \mathrm{E}-03$ & 7.101 & $* * *$ & \\
\hline isH16:isJun & 5.23E-02 & $6.43 \mathrm{E}-03$ & 8.135 & $* * *$ & \\
\hline isH17:isJun & $2.46 \mathrm{E}-02$ & $6.43 E-03$ & 3.832 & $* * *$ & \\
\hline isH18:isJun & $-5.61 E-02$ & $6.43 \mathrm{E}-03$ & -8.722 & $* * *$ & \\
\hline isH19:isJun & $-9.46 E-02$ & $6.43 \mathrm{E}-03$ & -14.705 & $* * *$ & \\
\hline isH20:isJun & $-1.09 E-01$ & $6.43 E-03$ & -16.954 & $* * *$ & \\
\hline isH21:isJun & $-9.57 E-02$ & $6.43 \mathrm{E}-03$ & -14.886 & $* * *$ & \\
\hline isH22:isJun & $-6.48 E-02$ & $6.43 E-03$ & -10.077 & $* * *$ & \\
\hline isH23:isJun & $-7.58 E-02$ & $6.43 E-03$ & -11.785 & $* * *$ & \\
\hline isH24:isJun & $-1.00 \mathrm{E}-01$ & $6.43 \mathrm{E}-03$ & -15.619 & $* * *$ & \\
\hline isH1:isJul & $3.20 \mathrm{E}-02$ & 4.87E-03 & 6.575 & $* * *$ & \\
\hline
\end{tabular}




\begin{tabular}{|c|c|c|c|c|c|}
\hline Variable & Estimate & Std. Error & $t$ value & Significance & Notes \\
\hline isH2:isJul & $-2.08 \mathrm{E}-04$ & 4.87E-03 & -0.043 & & \\
\hline isH3:isJul & $-2.92 \mathrm{E}-02$ & 4.87E-03 & -5.989 & $* * *$ & \\
\hline is 4 :is Jul & $-5.50 \mathrm{E}-02$ & 4.87E-03 & -11.277 & $* * *$ & \\
\hline isH5:isJul & $-7.81 \mathrm{E}-02$ & 4.87E-03 & -16.024 & $* * *$ & \\
\hline isH6:isJul & $-1.07 \mathrm{E}-01$ & 4.87E-03 & -21.898 & $* \star *$ & \\
\hline isH7:isJul & $-1.47 \mathrm{E}-01$ & 4.87E-03 & -30.174 & $* * *$ & \\
\hline isH8:isJul & $-1.16 \mathrm{E}-01$ & 4.87E-03 & -23.745 & $* * *$ & \\
\hline isH9:isJul & $-4.88 \mathrm{E}-02$ & 4.87E-03 & -10.005 & $* * *$ & \\
\hline isH10:isJul & $1.22 \mathrm{E}-02$ & 4.87E-03 & 2.506 & * & \\
\hline isH11:isJul & $6.73 \mathrm{E}-02$ & 4.87E-03 & 13.805 & $* * *$ & \\
\hline isH12:isJul & 1.15E-01 & 4.87E-03 & 23.651 & $* * *$ & \\
\hline isH13:isJul & $1.55 \mathrm{E}-01$ & 4.87E-03 & 31.861 & $* * *$ & \\
\hline isH14:isJul & $1.88 \mathrm{E}-01$ & 4.87E-03 & 38.54 & $* * *$ & \\
\hline isH15:isJul & 2.13E-01 & 4.87E-03 & 43.667 & $* * *$ & \\
\hline isH16:isJul & 2.22E-01 & 4.87E-03 & 45.468 & $* * *$ & \\
\hline isH17:isJul & 1.95E-01 & 4.87E-03 & 39.986 & $* * *$ & \\
\hline isH18:isJul & 1.15E-01 & 4.87E-03 & 23.547 & $* * *$ & \\
\hline isH19:isJul & $7.52 \mathrm{E}-02$ & 4.87E-03 & 15.427 & $* * *$ & \\
\hline isH20:isJul & $5.39 \mathrm{E}-02$ & $4.87 \mathrm{E}-03$ & 11.066 & $* * *$ & \\
\hline isH21:isJul & 5.97E-02 & 4.87E-03 & 12.257 & $* * *$ & \\
\hline isH22:isJul & 8.66E-02 & 4.87E-03 & 17.777 & $* * *$ & \\
\hline isH23:isJul & $8.02 \mathrm{E}-02$ & 4.87E-03 & 16.449 & $* * *$ & \\
\hline isH24:isJul & $6.22 \mathrm{E}-02$ & 4.87E-03 & 12.759 & $* * *$ & \\
\hline isH1:isAug & $-1.64 \mathrm{E}-02$ & 4.46E-03 & -3.688 & $* * \star$ & \\
\hline isH2:isAug & $-4.53 E-02$ & 4.46E-03 & -10.169 & $* * *$ & \\
\hline isH3:isAug & $-7.26 \mathrm{E}-02$ & 4.46E-03 & -16.293 & $* * *$ & \\
\hline isH4:isAug & $-9.68 \mathrm{E}-02$ & 4.46E-03 & -21.728 & $* * *$ & \\
\hline isH5:isAug & $-1.18 \mathrm{E}-01$ & 4.46E-03 & -26.52 & $* * *$ & \\
\hline isH6:isAug & $-1.39 \mathrm{E}-01$ & 4.46E-03 & -31.26 & $* * *$ & \\
\hline isH7:isAug & $-1.75 \mathrm{E}-01$ & 4.46E-03 & -39.168 & $* * *$ & \\
\hline isH8:isAug & $-1.58 \mathrm{E}-01$ & 4.46E-03 & -35.389 & $* * *$ & \\
\hline isH9:isAug & $-9.60 \mathrm{E}-02$ & 4.46E-03 & -21.55 & $* * *$ & \\
\hline isH10:isAug & $-3.73 E-02$ & 4.46E-03 & -8.371 & $* * *$ & \\
\hline isH11:isAug & $1.68 \mathrm{E}-02$ & 4.46E-03 & 3.768 & $* * *$ & \\
\hline isH12:isAug & $6.48 \mathrm{E}-02$ & 4.46E-03 & 14.53 & $* * *$ & \\
\hline isH13:isAug & $1.05 \mathrm{E}-01$ & 4.46E-03 & 23.497 & $* \star \star$ & \\
\hline isH14:isAug & $1.38 \mathrm{E}-01$ & 4.46E-03 & 30.883 & $* * \star$ & \\
\hline isH15:isAug & 1.63E-01 & 4.46E-03 & 36.456 & $* \star *$ & \\
\hline isH16:isAug & 1.70E-01 & 4.46E-03 & 38.225 & $* * *$ & \\
\hline isH17:isAug & 1.42E-01 & 4.46E-03 & 31.877 & $* * *$ & \\
\hline isH18:isAug & $6.01 \mathrm{E}-02$ & 4.46E-03 & 13.488 & $* * *$ & \\
\hline
\end{tabular}




\begin{tabular}{|c|c|c|c|c|c|}
\hline Variable & Estimate & Std. Error & $t$ value & Significance & Notes \\
\hline isH19:isAug & $1.88 \mathrm{E}-02$ & 4.46E-03 & 4.216 & $* * *$ & \\
\hline isH20:isAug & 3.67E-03 & 4.46E-03 & 0.824 & & \\
\hline isH21:isAug & $2.65 \mathrm{E}-02$ & 4.46E-03 & 5.954 & $* * *$ & \\
\hline isH22:isAug & $3.20 \mathrm{E}-02$ & 4.46E-03 & 7.176 & $* * *$ & \\
\hline isH23:isAug & 1.96E-02 & 4.46E-03 & 4.398 & $* * *$ & \\
\hline isH24:isAug & $2.70 \mathrm{E}-03$ & 4.46E-03 & 0.605 & & \\
\hline isH1:isSep & $-2.98 \mathrm{E}-02$ & 4.46E-03 & -6.696 & *** & \\
\hline isH2:isSep & $-5.31 E-02$ & 4.46E-03 & -11.917 & $* * *$ & \\
\hline isH3:isSep & $-7.32 \mathrm{E}-02$ & 4.46E-03 & -16.425 & $* * *$ & \\
\hline isH4:isSep & $-9.03 E-02$ & 4.46E-03 & -20.256 & $* * *$ & \\
\hline isH5:isSep & $-1.04 \mathrm{E}-01$ & 4.46E-03 & -23.34 & $* * *$ & \\
\hline isH6:isSep & $-1.09 E-01$ & 4.46E-03 & -24.482 & $* * *$ & \\
\hline isH7:isSep & $-1.07 \mathrm{E}-01$ & 4.46E-03 & -23.93 & $* * *$ & \\
\hline isH8:isSep & $-1.01 \mathrm{E}-01$ & 4.46E-03 & -22.575 & $* * *$ & \\
\hline isH9:isSep & $-5.78 \mathrm{E}-02$ & 4.46E-03 & -12.966 & $* * *$ & \\
\hline isH10:isSep & $-1.44 \mathrm{E}-02$ & 4.46E-03 & -3.23 & $* *$ & \\
\hline isH11:isSep & $2.45 \mathrm{E}-02$ & 4.46E-03 & 5.495 & $* * *$ & \\
\hline isH12:isSep & 5.76E-02 & 4.46E-03 & 12.923 & $* * *$ & \\
\hline isH13:isSep & 8.66E-02 & 4.46E-03 & 19.439 & $* * *$ & \\
\hline isH14:isSep & 1.12E-01 & 4.46E-03 & 25.06 & $* * *$ & \\
\hline isH15:isSep & $1.30 \mathrm{E}-01$ & 4.46E-03 & 29.233 & $* * *$ & \\
\hline isH16:isSep & $1.35 \mathrm{E}-01$ & 4.46E-03 & 30.333 & $* * \star$ & \\
\hline isH17:isSep & $1.07 \mathrm{E}-01$ & 4.46E-03 & 23.973 & $* * *$ & \\
\hline isH18:isSep & 2.60E-02 & 4.46E-03 & 5.827 & $* * *$ & \\
\hline isH19:isSep & $-6.25 \mathrm{E}-03$ & 4.46E-03 & -1.402 & & \\
\hline isH20:isSep & $2.16 \mathrm{E}-02$ & 4.46E-03 & 4.85 & $* * *$ & \\
\hline isH21:isSep & $3.75 \mathrm{E}-02$ & 4.46E-03 & 8.426 & $* * *$ & \\
\hline isH22:isSep & 2.60E-02 & 4.46E-03 & 5.833 & $* * *$ & \\
\hline isH23:isSep & $6.89 \mathrm{E}-03$ & 4.46E-03 & 1.546 & & \\
\hline isH24:isSep & $-1.38 \mathrm{E}-02$ & 4.46E-03 & -3.092 & $* *$ & \\
\hline isH1:isOct & $-1.58 \mathrm{E}-02$ & 4.39E-03 & -3.603 & $* * *$ & \\
\hline isH2:isOct & $-3.01 \mathrm{E}-02$ & 4.37E-03 & -6.88 & $* * *$ & \\
\hline isH3:isOct & $-4.09 E-02$ & 4.39E-03 & -9.321 & $* * *$ & \\
\hline isH4:isOct & $-4.90 \mathrm{E}-02$ & 4.39E-03 & -11.16 & $* * *$ & \\
\hline isH5:isOct & $-5.29 E-02$ & 4.39E-03 & -12.041 & $* * *$ & \\
\hline isH6:isOct & $-4.45 \mathrm{E}-02$ & 4.39E-03 & -10.139 & $* * *$ & \\
\hline isH7:isOct & $-2.13 \mathrm{E}-02$ & 4.39E-03 & -4.856 & $* \star *$ & \\
\hline isH8:isOct & -7.67E-03 & 4.39E-03 & -1.747 & . & \\
\hline isH9:isOct & 1.05E-02 & 4.39E-03 & 2.385 & * & \\
\hline isH10:isOct & 2.83E-02 & 4.39E-03 & 6.433 & $* * *$ & \\
\hline isH11:isOct & 4.42E-02 & 4.39E-03 & 10.054 & *** & \\
\hline
\end{tabular}




\begin{tabular}{|c|c|c|c|c|c|}
\hline Variable & Estimate & Std. Error & $t$ value & Significance & Notes \\
\hline isH12:isOct & $5.69 \mathrm{E}-02$ & 4.39E-03 & 12.957 & $* * *$ & \\
\hline isH13:isOct & 6.84E-02 & 4.39E-03 & 15.579 & $* * *$ & \\
\hline isH14:isOct & 7.81E-02 & 4.39E-03 & 17.787 & $* * *$ & \\
\hline isH15:isOct & 8.38E-02 & 4.39E-03 & 19.08 & $* \star \star$ & \\
\hline isH16:isOct & 8.03E-02 & 4.39E-03 & 18.285 & $* * *$ & \\
\hline isH17:isOct & $5.32 \mathrm{E}-02$ & 4.39E-03 & 12.111 & $* * *$ & \\
\hline isH18:isOct & $-9.08 \mathrm{E}-03$ & 4.39E-03 & -2.068 & * & \\
\hline isH19:isOct & $6.64 \mathrm{E}-03$ & 4.39E-03 & 1.512 & & \\
\hline isH20:isOct & 3.95E-02 & 4.39E-03 & 9 & $* * *$ & \\
\hline isH21:isOct & 3.66E-02 & 4.39E-03 & 8.328 & $* * *$ & \\
\hline isH22:isOct & 2.86E-02 & $4.39 \mathrm{E}-03$ & 6.518 & $* * *$ & \\
\hline isH23:isOct & $1.45 \mathrm{E}-02$ & 4.39E-03 & 3.31 & $* * *$ & \\
\hline isH24:isOct & -1.47E-04 & 4.39E-03 & -0.034 & & \\
\hline is $\mathrm{H} 1$ :isNov & $2.60 \mathrm{E}-03$ & 4.49E-03 & 0.58 & & \\
\hline isH2:isNov & $-4.65 \mathrm{E}-03$ & $4.48 \mathrm{E}-03$ & -1.038 & & \\
\hline isH3:isNov & -8.86E-03 & 4.49E-03 & -1.974 & * & \\
\hline isH4:isNov & $-1.12 \mathrm{E}-02$ & 4.49E-03 & -2.498 & * & \\
\hline isH5:isNov & $-9.79 \mathrm{E}-03$ & 4.49E-03 & -2.182 & * & \\
\hline isH6:isNov & $-1.49 \mathrm{E}-03$ & 4.49E-03 & -0.332 & & \\
\hline isH7:isNov & $5.94 \mathrm{E}-03$ & 4.49E-03 & 1.322 & & \\
\hline isH8:isNov & 7.00E-03 & 4.49E-03 & 1.56 & & \\
\hline isH9:isNov & 2.09E-02 & 4.49E-03 & 4.651 & $* * *$ & \\
\hline isH10:isNov & 2.85E-02 & 4.49E-03 & 6.359 & $* \star \star$ & \\
\hline isH11:isNov & 3.29E-02 & 4.49E-03 & 7.317 & $* * *$ & \\
\hline isH12:isNov & 3.69E-02 & 4.49E-03 & 8.21 & $* * *$ & \\
\hline isH13:isNov & 4.02E-02 & 4.49E-03 & 8.947 & $* * *$ & \\
\hline isH14:isNov & 4.31E-02 & 4.49E-03 & 9.593 & $* * \star$ & \\
\hline isH15:isNov & 4.51E-02 & 4.49E-03 & 10.055 & $* * *$ & \\
\hline isH16:isNov & 4.61E-02 & 4.49E-03 & 10.274 & $* * *$ & \\
\hline isH17:isNov & 5.34E-02 & 4.49E-03 & 11.902 & $* * *$ & \\
\hline isH18:isNov & $5.26 \mathrm{E}-02$ & 4.49E-03 & 11.725 & $* * *$ & \\
\hline isH19:isNov & 3.96E-02 & 4.49E-03 & 8.821 & $* * *$ & \\
\hline isH20:isNov & 3.56E-02 & 4.49E-03 & 7.937 & $* * *$ & \\
\hline isH21:isNov & 3.16E-02 & 4.49E-03 & 7.04 & $* * *$ & \\
\hline isH22:isNov & 2.63E-02 & 4.49E-03 & 5.866 & $* \star *$ & \\
\hline isH23:isNov & 1.96E-02 & 4.49E-03 & 4.367 & $* * *$ & \\
\hline isH24:isNov & 1.17E-02 & 4.49E-03 & 2.606 & ** & \\
\hline isH1:isDec & $6.70 \mathrm{E}-02$ & 6.10E-03 & 10.989 & $* * *$ & \\
\hline isH2:isDec & 5.89E-02 & 6.10E-03 & 9.648 & $* * *$ & \\
\hline isH3:isDec & 5.42E-02 & 6.10E-03 & 8.888 & $* \star \star$ & \\
\hline is 4 4:isDec & $5.22 \mathrm{E}-02$ & $6.10 \mathrm{E}-03$ & 8.562 & $* * *$ & \\
\hline
\end{tabular}




\begin{tabular}{|c|c|c|c|c|c|}
\hline Variable & Estimate & Std. Error & $t$ value & Significance & Notes \\
\hline isH5:isDec & 5.19E-02 & $6.10 \mathrm{E}-03$ & 8.504 & $* * *$ & \\
\hline isH6:isDec & 5.17E-02 & $6.10 \mathrm{E}-03$ & 8.474 & $* * *$ & \\
\hline isH7:isDec & 4.89E-02 & $6.10 \mathrm{E}-03$ & 8.014 & $* * *$ & \\
\hline isH8:isDec & 4.92E-02 & $6.10 \mathrm{E}-03$ & 8.062 & $* * *$ & \\
\hline isH9:isDec & $5.66 \mathrm{E}-02$ & $6.10 \mathrm{E}-03$ & 9.27 & $* * *$ & \\
\hline isH10:isDec & 5.94E-02 & $6.10 \mathrm{E}-03$ & 9.731 & $* * *$ & \\
\hline isH11:isDec & 5.78E-02 & $6.10 \mathrm{E}-03$ & 9.474 & $* * *$ & \\
\hline isH12:isDec & 5.65E-02 & $6.10 \mathrm{E}-03$ & 9.261 & $* * *$ & \\
\hline isH13:isDec & $5.60 \mathrm{E}-02$ & $6.10 \mathrm{E}-03$ & 9.173 & $* * *$ & \\
\hline isH14:isDec & 5.63E-02 & $6.10 \mathrm{E}-03$ & 9.236 & $* * *$ & \\
\hline isH15:isDec & 5.87E-02 & $6.10 \mathrm{E}-03$ & 9.629 & $* * *$ & \\
\hline isH16:isDec & 6.36E-02 & $6.10 \mathrm{E}-03$ & 10.424 & $* * *$ & \\
\hline isH17:isDec & $8.52 \mathrm{E}-02$ & $6.10 \mathrm{E}-03$ & 13.959 & $* * *$ & \\
\hline isH18:isDec & $9.40 \mathrm{E}-02$ & $6.10 \mathrm{E}-03$ & 15.415 & $* * *$ & \\
\hline isH19:isDec & $8.29 \mathrm{E}-02$ & $6.10 \mathrm{E}-03$ & 13.583 & $* * *$ & \\
\hline isH20:isDec & 8.25E-02 & $6.10 \mathrm{E}-03$ & 13.517 & $* * *$ & \\
\hline isH21:isDec & 8.52E-02 & $6.10 \mathrm{E}-03$ & 13.966 & $* * *$ & \\
\hline isH22:isDec & $8.88 \mathrm{E}-02$ & $6.10 \mathrm{E}-03$ & 14.562 & $* * *$ & \\
\hline isH23:isDec & $8.88 \mathrm{E}-02$ & $6.10 \mathrm{E}-03$ & 14.552 & $* * *$ & \\
\hline isH24:isDec & 8.01E-02 & $6.10 \mathrm{E}-03$ & 13.127 & $* * *$ & \\
\hline isFeb:sun.hours & $-9.87 E-04$ & $6.10 \mathrm{E}-05$ & -16.182 & $* * *$ & \\
\hline isMar:sun.hours & $-1.26 \mathrm{E}-03$ & $5.75 \mathrm{E}-05$ & -21.895 & $* * *$ & \\
\hline isApr:sun.hours & $-1.08 \mathrm{E}-03$ & 5.84E-05 & -18.453 & $* * *$ & \\
\hline isMay:sun.hours & $-3.01 \mathrm{E}-04$ & $6.44 \mathrm{E}-05$ & -4.669 & $* * *$ & \\
\hline isJun:sun.hours & $2.72 \mathrm{E}-03$ & $1.42 \mathrm{E}-04$ & 19.115 & $* * *$ & \\
\hline isJul:sun.hours & $-1.60 \mathrm{E}-03$ & $8.11 \mathrm{E}-05$ & -19.676 & $* * *$ & \\
\hline isAug:sun.hours & $-2.11 \mathrm{E}-04$ & $5.98 \mathrm{E}-05$ & -3.536 & $* * *$ & \\
\hline isSep:sun.hours & $-2.08 \mathrm{E}-04$ & $5.90 \mathrm{E}-05$ & -3.519 & $* * *$ & \\
\hline isOct:sun.hours & $-7.26 \mathrm{E}-04$ & $5.78 \mathrm{E}-05$ & -12.549 & $* * *$ & \\
\hline isNov:sun.hours & $-1.03 E-03$ & $6.69 \mathrm{E}-05$ & -15.318 & $* * *$ & \\
\hline isDec:sun.hours & $-2.88 \mathrm{E}-03$ & 1.92E-04 & -14.989 & $* * *$ & \\
\hline
\end{tabular}

\section{Table A.3. Temperature calculations}

$$
\begin{array}{ll}
\operatorname{Tmax}_{D}=\max \operatorname{Tadj}_{i}, & \forall i \in D \\
\operatorname{Tmin}_{D}=\min \operatorname{Tadj}_{i} & \forall i \in D
\end{array}
$$$$
\operatorname{Tmax} . H D D=\max (69-\operatorname{Tmax}, 0)
$$ 
$\operatorname{Tmax} . C D D=\max (\operatorname{Tmax}-69,0)$

$\operatorname{Tmin} . H D D=\max \left(45-\operatorname{Tmin}_{D}, 0\right)$

$\operatorname{Tmin} . C D D=\max \left(\operatorname{Tmin}_{D}-45,0\right)$

$i=$ hour of the day

$D=$ day of the year

$\operatorname{Tadj}_{i}=$ hourly adjusted temperature

$\operatorname{Tmax}_{D}, \operatorname{Tm} \min D=$ daily $\max$ and $\min$ temperature $\left[{ }^{\circ} \mathrm{F}\right]$

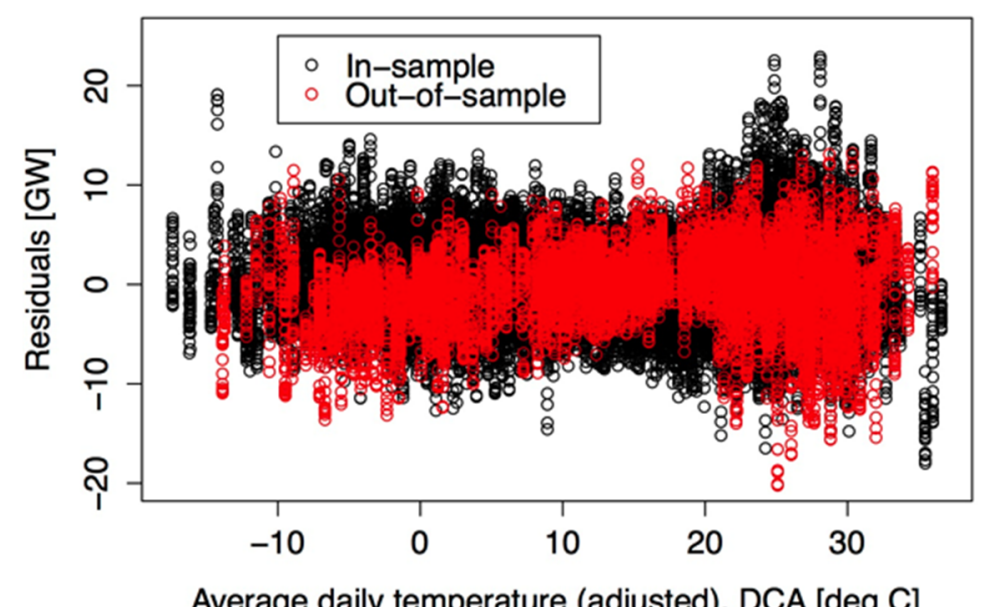

Figure A.2. In-sample and out-of-sample residuals for PJM, linear model. Residuals are large at high temperature days.

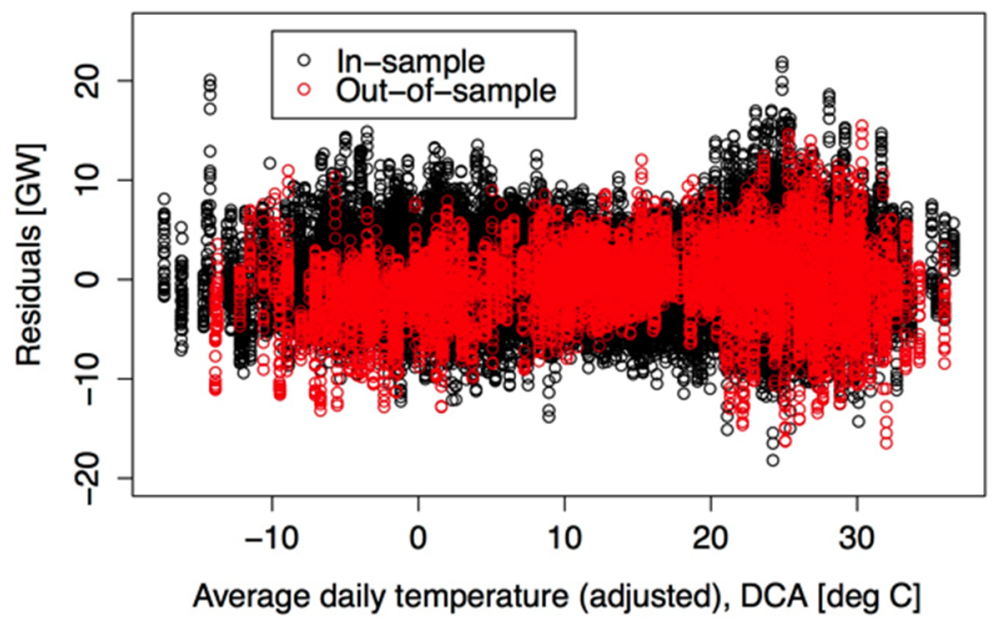


Figure A.3. In-sample and out-of-sample residuals for PJM, non-linear model. The model is more accurate at predicting load during high temperature days than the linear model.

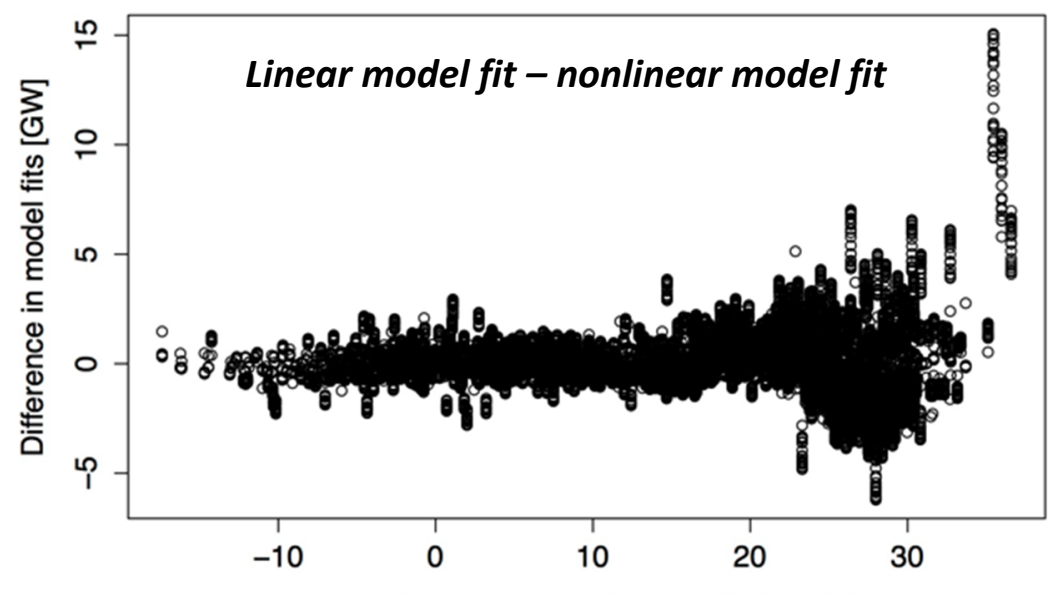

Average daily temperature (adjusted), DCA [deg C]

Figure A.4. Difference in linear and nonlinear model fits, when predicting load out-ofsample.

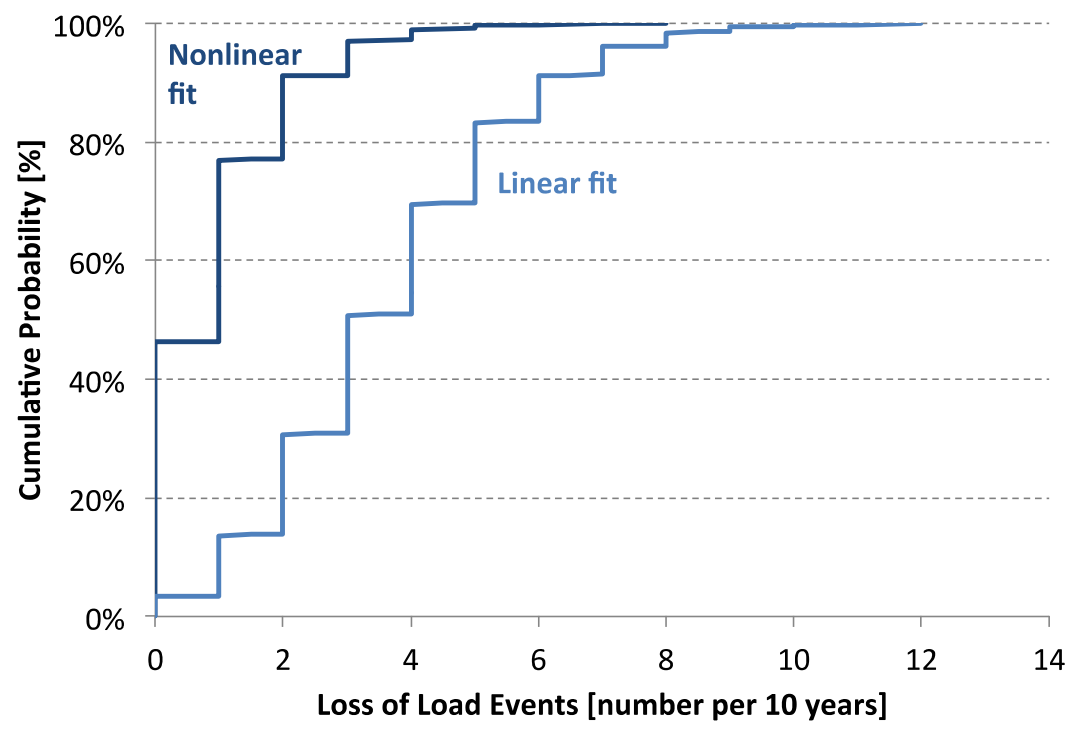

Figure A.5. Calculated LOLE for linear and nonlinear models 


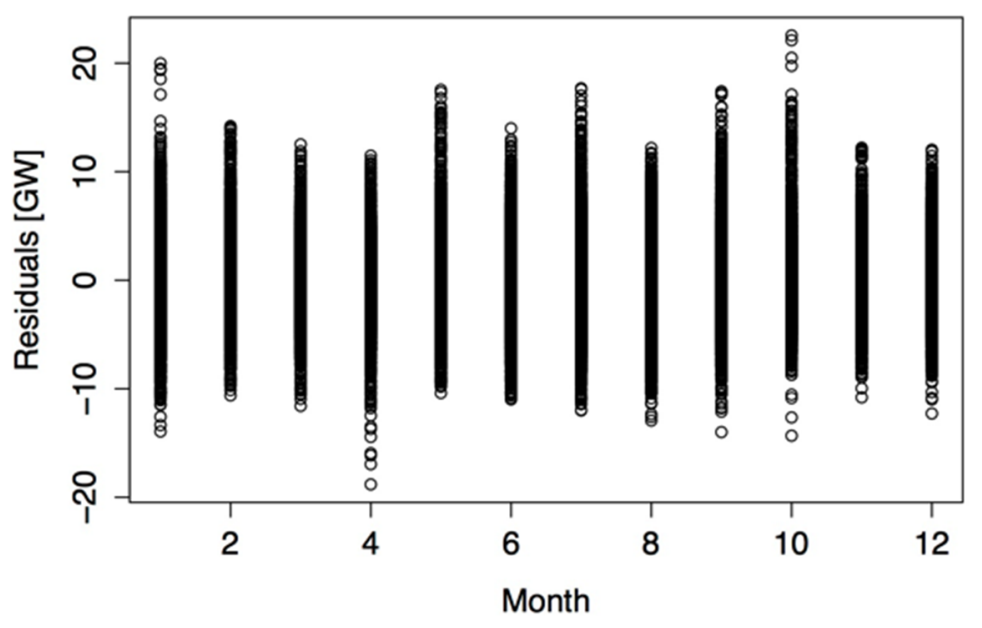

Figure A.6. In-sample residuals, by month

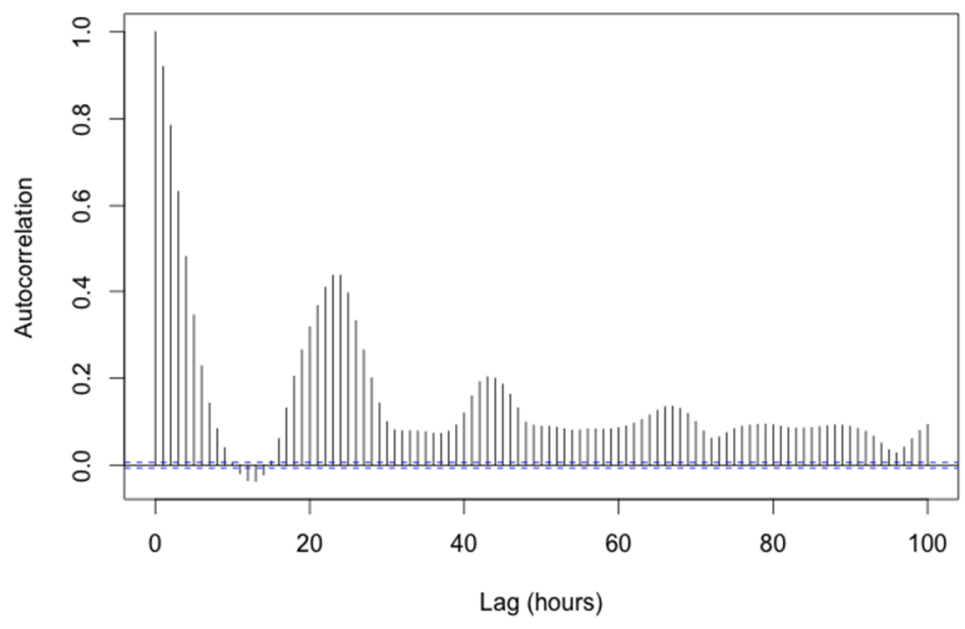

Figure A.7. Autocomelation of in-sample residuals 


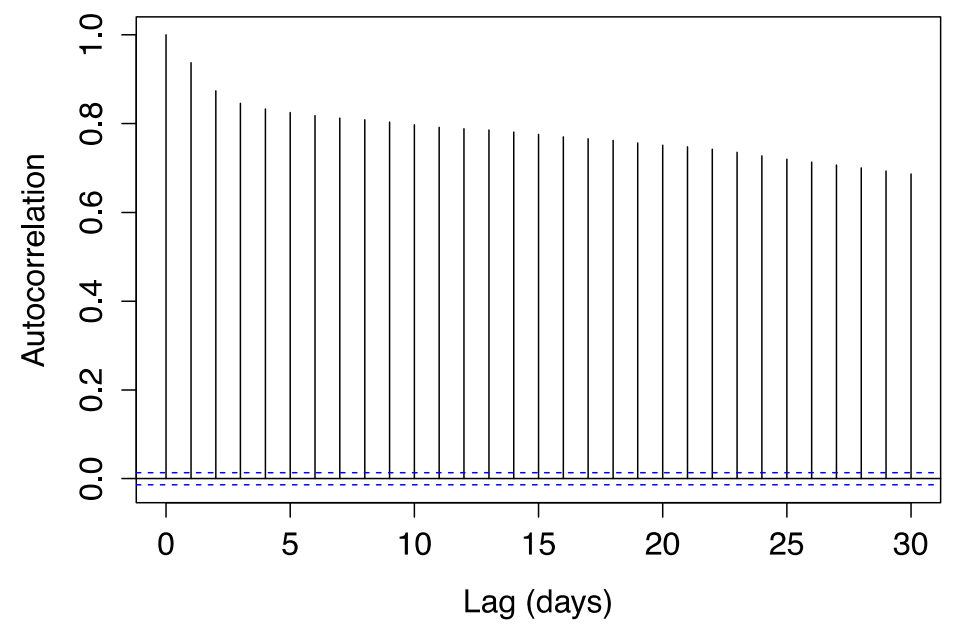

Figure A.8. Autocomelation function, average adjusted daily temperature. Data is for years 1949 - 2010, except 1966 - 1972.

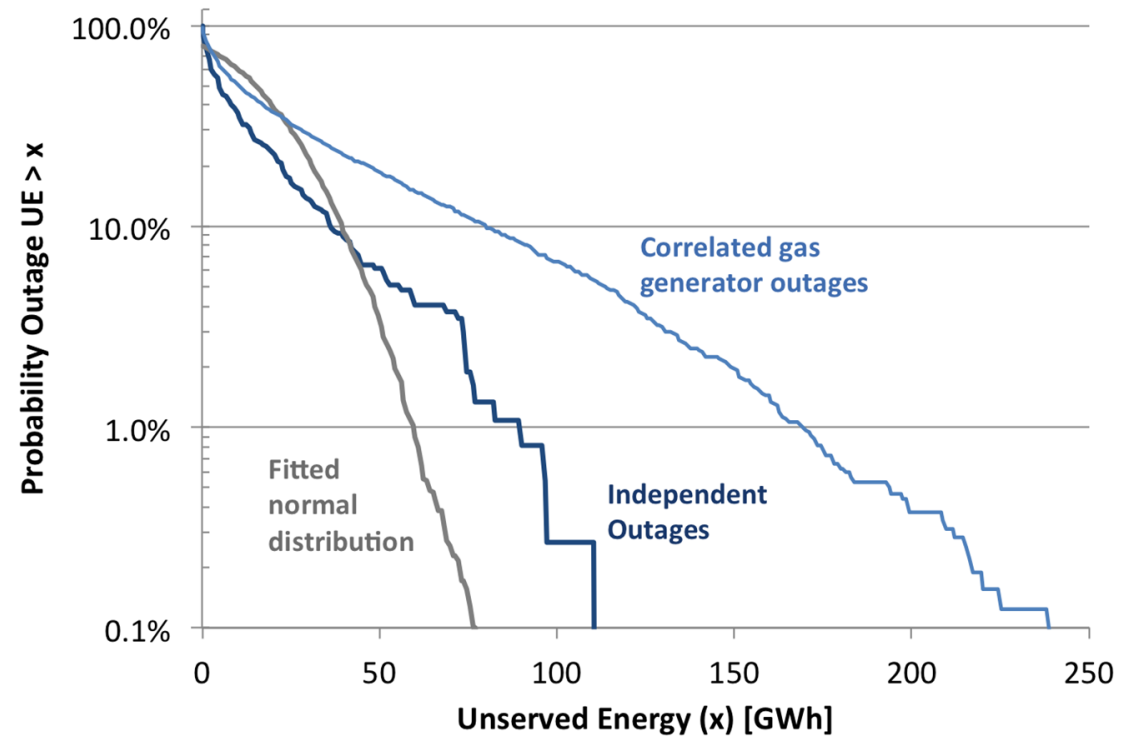

Figure A.9. Distribution of outage size, in terms of unserved energy. Shown are both scenario in which outages are independent, and a scenario in which a natural gas supply shortage occurs on average once per year, forcing all gas generators offline at once. Assumed reserve margin is $\mathbf{1 5 . 5 \%}$. 